\title{
Reproductive performance in a select sample of dairy herds
}

\author{
James D. Ferguson ${ }^{* 1}$ and Andrew Skidmore† \\ *University of Pennsylvania, School of Veterinary Medicine, Kennett Square 19348 \\ †Merck Animal Health, Alexander, NY 14005
}

\section{ABSTRACT}

Sixteen herds were selected from a pool of 64 herds nominated by consultants for participation in a national survey to demonstrate excellence in reproductive performance. For inclusion in the survey, herds had to have comprehensive records in a farm computer database or participate in a Dairy Herd Improvement Association record system and have superior reproductive performance as judged by the herd advisor. Herd managers were asked to fill out a questionnaire to describe their reproductive management practices and provide herd records for data analysis. Reproductive analysis was based on individual cow records for active and cull dairy cows that calved during the calendar year 2010. Breeding records by cow were used to calculate indices for insemination rate (IR), conception rate (CR), pregnancy rate (PR), and culling. Herds ranged in size from 262 to 6,126 lactating and dry cows, with a mean of 1,654 [standard deviation (SD) 1,494] cows. Mean days to first insemination (DFS) was $71.2 \mathrm{~d}$ (SD $4.7 \mathrm{~d}$ ), and IR for first insemination was $86.9 \%$. Mean days between inseminations were $33.4 \mathrm{~d}$ (SD $3.1 \mathrm{~d}$ ), and $15.4 \%$ of insemination intervals were greater than $48 \mathrm{~d}$ (range: 7.2 to $21.5 \%$ ). First-service conception rate was $44.4 \%$ (SD 4.8\%) across all herds and ranged from 37.5 to $51.8 \%$. Mean PR was $32.0 \%$ (SD $3.9 \%$ ) with a range of 26.5 to $39.4 \%$. Lactation cull rate was $32.2 \%$ (SD $12.4 \%$ ) with a range from 13.6 to $58.1 \%$. Compared with mean data and SD for herds in the Raleigh Dairy Herd Improvement Association system, mean indices for these herds ranked them in the 99th percentile for IR (using heat detection rate as comparison), 99th percentile for PR, the bottom 18.6 percentile for DFS, and around the 50th percentile for CR. This suggests that excellent herd reproductive performance was associated with reproductive management that resulted in high insemination rates combined with average CR.

Key words: reproduction, management, dairy cow

Received June 4, 2012.

Accepted October 7, 2012.

${ }^{1}$ Corresponding author: ferguson@vet.upenn.edu

\section{INTRODUCTION}

Reproductive performance has declined in dairy herds over the last 2 generations associated with changes in management practices, housing, and milk production (Lucy, 2001; Weigel, 2006). In part, performance has declined due to a reduction in reproductive biology of dairy cows, apparent as an increase in inseminations per pregnancy. Fertility has decreased coincident with increases in milk production, cows per worker, and time spent within confinement housing, along with a decrease in expression of estrus by the high-producing cow (Willard et al., 2003; Lopez et al., 2004a,b; Grimard et al., 2006). The effect has been to increase days open, from $110 \mathrm{~d}$ in 1965 to $150 \mathrm{~d}$ in 2005 (USDA AIPL summary data: http://aipl.arsusda.gov/reference/fertility/ gentrd.htm; accessed May 2012). The minimum mean projected days open in the Raleigh Dairy Records Management System (DRMS) data was 156.8 d (SD 42.0 d, Table 1; Raleigh DRMS, 2012).

Following an insemination, pregnancy outcome is variable across farms by days postinsemination (Grimard et al., 2006). Given good insemination technique, $60 \%$ or more of ovulated ovum fertilize (Grimard et al., 2006). However, due to embryonic death, pregnancy outcome declines so that by 30 to $40 \mathrm{~d}$ postinsemination, only 30 to $50 \%$ of cows may be diagnosed as pregnant (Santos et al., 2004; Grimard et al., 2006). Reported conception rate (CR) at first insemination is $43.4 \%$ (SD 20.6\%) in the Raleigh, North Carolina DHIA system (Table 1; Raleigh DRMS, 2012).

Detection of estrus (heat detection rate, HDR) is estimated at $43.4 \%$ (SD 16.8\%) by Raleigh DRMS (2012; Table 1), indicating that less than half of the possible estrus events are observed. Many factors influence detection of estrus, including number of prior estruses and DIM, number of contemporary cows in estrus, duration of standing estrus, flooring surface, and management factors such as observation frequency and duration and use of secondary aids (Britt et al., 1986; Heersche and Nebel, 1994; Lopez et al., 2004a,b; Sveberg et al., 2011). In general, HDR is greater in the Jersey breed than in the Holstein breed (Norman et al., 2009). Because estrus detection controls insemination 
Table 1. Reproductive metrics (mean, SD in parentheses) for herds (all breeds) subscribing to Raleigh DRMS record system (Raleigh DRMS, 2012)

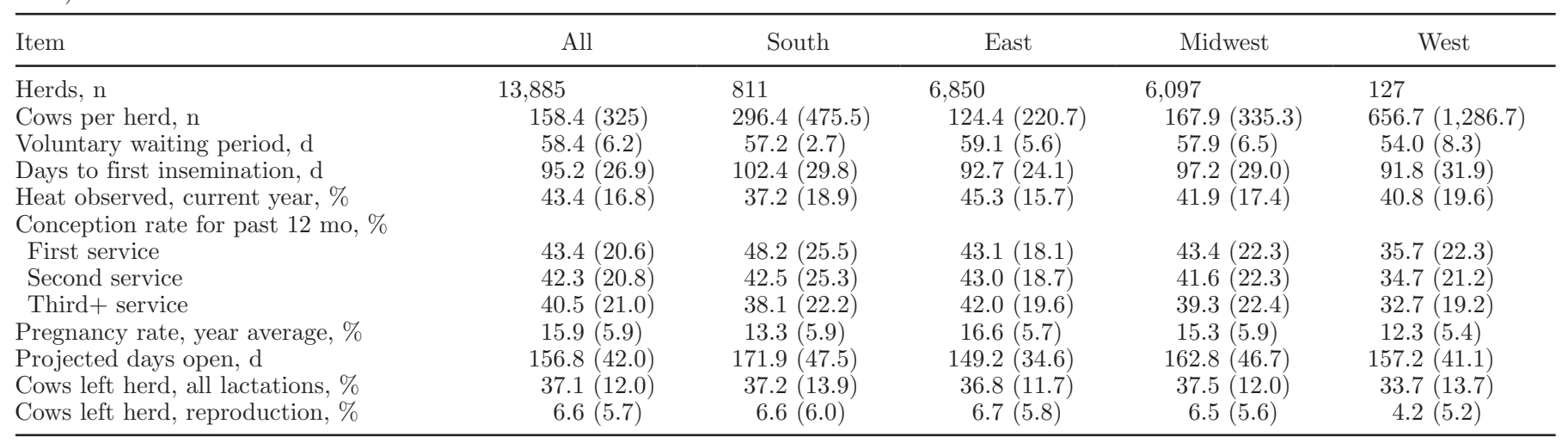

rate or frequency (IR), it is a major control point of reproductive efficiency.

Conception rate ranges from 43.4 to $40.5 \%$ for first to third service (Table 1; Raleigh DRMS, 2012). Many factors influence $\mathrm{CR}$ in lactating dairy cows, including metabolic and infectious disease and environmental conditions (Coleman et al., 1985; Sheldon et al., 2006; Garnsworthy et al., 2008). Nonbiologic factors, such as thawing of semen straws and insemination technique, use of sprinklers in holding pens, and density of housing groups also influence $\mathrm{CR}$ and service rates (Schefers et al., 2010). Of particular concern is the association of higher milk production with lower CR, possibly due to lesser body condition (Lucy, 2001; Weigel, 2006). In general, the Jersey breed has greater CR than the Holstein breed in the United States (Norman et al., 2009).

Establishing pregnancy postcalving at early DIM is associated with high economic returns (Oltenacu et al., 1981). Inchaisri et al. (2011) observed that the optimum time to pregnancy was less than $10 \mathrm{wk}$ for most dairy cows, and pregnancy after 6 wk reduced economic returns. In general, postpartum physiology delays how early postcalving insemination may recommence. Cows must resume ovulation and uterine involution must be complete, processes that usually take 30 to $50 \mathrm{~d}$ postcalving. The time at which a producer may begin insemination postcalving is referred to as the voluntary waiting period (VWP). Typically, producers have used a VWP of 40 to $60 \mathrm{~d}$ to begin insemination programs. Due to the shape of the lactation curve, extending the VWP may increase economic losses but, with increased milk production, some authors have observed longer VWP associated with increased CR (Tenhagen et al., 2004; Schefers et al., 2010). Therefore, producers must determine the trade-off between CR and VWP. Often VWP is not rigidly applied within a herd, as cows observed in estrus just before a reported VWP may be inseminated or cows perceived to have lower potential fertility may be delayed in first insemination past the VWP. Because of the fuzzy nature of VWP within dairy herds, some producers have used rules of proportion of first insemination of 5\% (Schefers et al., 2010) or $10 \%$ (Miller et al., 2007) to define an observed VWP (oVWP) for a herd. One of the authors (JDF) has used the DIM by which $5 \%$ of first inseminations have occurred as an estimate of oVWP and found it to be a precise index by which to evaluate reproductive management. The oVWP is important because management should desire to have cows become pregnant rapidly after the oVWP (Ferguson and Galligan, 1993a,b).

Reproductive efficiency is an outcome of IR and CR within a herd, which can be combined in a variable termed pregnancy rate (PR; Ferguson and Galligan, 1993a,b). Pregnancy rate determines the proportion of nonpregnant cows that become pregnant every 21 $\mathrm{d}$ from the oVWP, and it is the main determinant of days open and economic returns associated with reproduction (Ferguson and Galligan, 1993a,b). Low HDR resulting in low IR combined with low CR dramatically lowers PR and reproductive efficiency. Higher milk production has been associated not only with lower CR but also with lesser and shorter expression of estrus and a decline in PR (Lopez et al., 2004a; Weigel, 2006). Mean PR for herds subscribing to Raleigh DRMS records was $15.9 \%$ (SD 5.9\%; Table 1; Raleigh DRMS, 2012). Increasing $P R$ reduces days open and increases revenue per cow (Heersche and Nebel, 1994; Meadows et al., 2005). Low PR reduces milk produced per day and calves born per year and reduces income associated with reproduction. The number of replacement animals raised within a herd may be limited when PR declines below $20 \%$.

Intensity of insemination may be defined as the number of cows inseminated within a 21-d period divided by the number of cows available to inseminate. 
Insemination rates may be used as a proxy for HDR when evaluating reproductive management. Intensity of insemination is related to HDR, but may also be elevated from use of synchronized, timed AI (TAI) programs that do not rely on estrus detection (Pursley et al., 1997; Fricke et al., 2003). As intensity of insemination increases, as long as CR remains reasonable, days open decrease and PR increases as more cows are inseminated and become pregnant within $21 \mathrm{~d}$ from the VWP (Morton, 2010; Giordano et al., 2011). Timed AI programs have greatly improved insemination rates for first insemination (Pursley et al., 1997; Fricke et al., 2003; Miller et al., 2007). However, once inseminated, cows not pregnant must be either observed for return to estrus or diagnosed as open to be assigned to a rebreeding program. Days between inseminations can be controlled either through aggressive estrus detection or through timely, routine diagnosis of nonpregnant status and assigning cows to a TAI postsynchronization program. Diagnosis of nonpregnancy is limited by the type of test (ultrasound, rectal palpation, blood pregnancy test) and the time following insemination at which a test may be performed with high sensitivity and specificity. Because of high rates of embryonic death, which mimic low specificity of pregnancy test (i.e., false positives, the test indicates pregnant, but the cow is soon found open by estrus detection), nonpregnancy tests are not efficient until 28 to $40 \mathrm{~d}$ postinsemination. Intensity of reinsemination is limited by embryonic death, estrus detection, and timeliness of nonpregnancy diagnosis. Postinsemination synchronization programs have been combined with routine pregnancy test diagnosis to decrease days to reinsemination (Dewey et al., 2010).

Other strategies to improve insemination intensity include more frequent observations to detect estrus (Pennington et al., 1986), use of heat detection aids such as paint or markers applied to the pelvic tail head region (Pennington et al., 1986), and use of activity monitors and electronic mount detectors (Dransfield et al., 1998; Fricke et al., 2003). Application of appropriate management tools can aid in control of insemination frequency. Reproductive outcomes are then a function of cow biology and insemination technique. Pregnancy outcome after an insemination is a complex interaction of cow health and environmental interactions, in addition to inseminator skill (Oltenacu et al., 1981; Grimard et al., 2006). Observed reproductive performance is a combination of cow biology and the management program used to control first and repeat inseminations.

The interaction of cow biology and management can be assessed from farm records constructed from reproductive events following calving for each cow. Events include calving date, insemination date(s), pregnancy outcome, and herd removal (if appropriate). Patterns of insemination for first and repeat insemination(s) can be used to assess herd reproductive management, which is a combination of estrus detection and TAI. Pregnancy outcome for each service number, parity group, and season offers a picture of cow biology within a herd and can be used to calculate estimates of CR. Conception rate may also be confounded by inseminator skill and semen handling technique independent of cow biology. Excellent reproductive performance is a combination of good management control of insemination and good cow biology.

For this study, we selected herds with excellent reproductive performance to share herd records and information concerning their reproductive management program and thus provide a picture of cow biology and management associated with excellent performance. Reproductive performance was assessed using a consistent methodology across all herds. The goal of this project was to summarize reproductive performance and management on these farms. The intent was that this information would provide information for extension agents, veterinarians, farm managers, and other industry advisors to encourage producers that excellent reproductive performance is possible.

\section{MATERIALS AND METHODS}

Industry advisors were notified to submit herds with excellent reproductive performance to be nominated for Dairy Cattle Reproductive Council (DCRC; http:// www.dcrcouncil.org) reproductive awards. The goal of this award was to honor and learn from dairy producers who have successfully implemented management procedures that achieve high reproductive efficiency. Managers of the nominated herds completed a short survey that was submitted to a panel of judges for screening (survey available at http://www.dcrcouncil. org/reproduction-awards.aspx). From the initial surveys, herds were selected for a final round of evaluation. More information on the DCRC reproductive awards is available at the DCRC website (http://www.dcrcouncil. org). Selected herds provided herd records in June and July 2011, which were used to evaluate reproductive performance for cows that had calved between January 1 and December 31, 2010. Each submitted data set was analyzed by one of the authors (JDF). In addition, a more extensive survey was filled out by each nominating industry advisor concerning reproductive management (available at http://www.dcrcouncil.org/reproductionawards.aspx). Sixteen herds submitted data for analysis. All herd identification was confidential but location of herds was as follows: 5 herds each in Wisconsin and New York, 2 herds in California, and 1 herd each in Iowa, Washington, Oregon, and South Dakota. 
Farm records were submitted either from herd software (DairyComp305, Valley Ag Software, Tulare, CA) or as an offload file from the herd DHIA organization. The process of data analysis is outlined in Table 2 . First, for each farm, data were extracted by cow for lactation number (parity), calving date for current lactation, total services, individual breeding dates for first through seventh and last insemination, reproductive code (pregnant, open, inseminated), previous calving interval (for cows in second and higher lactations), previous service number (for cows in second and higher lactations), date left herd and code for reason (if a cull cow), and projected 305-d milk yield (Table 2). Reproductive data were analyzed from active cows in the herd (lactating and dry) and from animals that had been culled during the last $365 \mathrm{~d}$.

In step 2 (Table 2), data were then used to calculate days to first insemination (DFS), DIM last insemination (date last insemination - date of calving), days between inseminations (BI, date subsequent insemination - date prior insemination, if applicable), and DIM left herd, if culled. An oVWP was calculated for each herd based on distribution of DFS. Days to first insemination were distributed from least to greatest; a value for the oVWP was assigned based on the days by which either $5 \%$ of DFS were counted or a distinct cluster of DFS was apparent, as with synchronized TAI programs.

Third (step 3, Table 2), previous calving interval and previous service number were used to adjust each mul- tiparous cow to their previous calving date. This step created a data set with breeding information for the current and previous lactations for each cow. Because cows that have calved in the 4 mo before the current month contribute little information to current conception estimates, and because cows with short CI recalve at higher frequencies than cows with long CI, estimates of CR that are calculated using only current lactation data from active cows underestimate CR. Estimates of CR from current lactation data over-represent cows with repeat services and long days open and underrepresent cows with few services and short days open. Step 3 adjusted data to establish a balanced cohort of cows to analyze reproductive events for cows that calved within a 1-yr period from January 1 through December 31, 2010 (XsysC, 4 to 16 mo before current month). All calculations were performed on this data using the oVWP as a reference point for initiation of insemination.

In step 4, IR was estimated from patterns of insemination for first and repeat insemination using frequency distributions (Table 2). First insemination rate (FSTIR) was estimated by distributing DFS in 21-d periods from the oVWP for each herd. Within each 21-d period, the number of cows available to inseminate divided by the number of cows available to inseminate estimated FSTIR within the interval. The days between first and second, second and third, and third and fourth inseminations were distributed for each herd in the following categories: $<10 \mathrm{~d}$ (a10),

Table 2. Steps in the process of analysis of reproductive data from 16 herds selected for Dairy Cattle Reproductive Council award

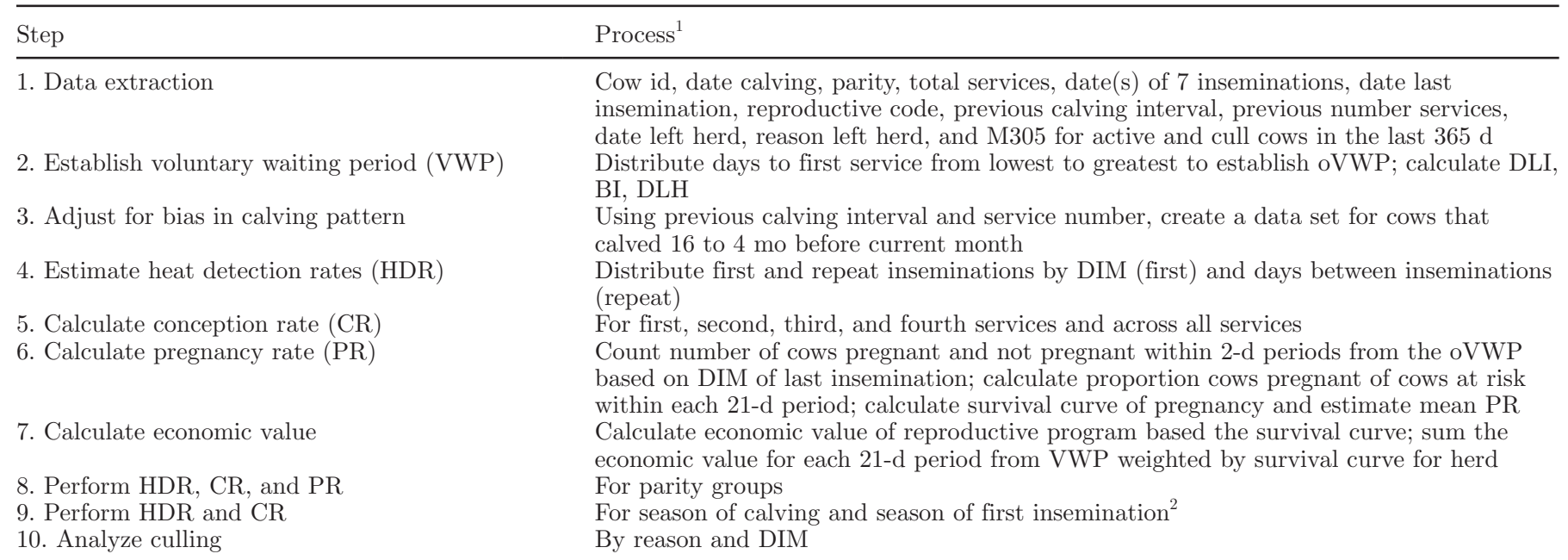

${ }^{1} \mathrm{M} 305=$ projected or actual 305-d milk yield; oVWP $=$ observed VWP, defined either as DIM when $5 \%$ of first inseminations had occurred or as the lowest DIM at first insemination if a cluster was apparent; DLI = DIM at last insemination; BI = days between sequential inseminations, first to second, second to third, third to fourth; DLH = DIM left herd for cull cows.

${ }^{2}$ Seasons: winter $=$ December, January, February; spring = March, April, May; summer = June, July, August; fall = September, October, November. 
Table 3. Example calculation of conception rate data ${ }^{1}$

\begin{tabular}{|c|c|c|c|c|c|c|}
\hline Service number & $\begin{array}{l}\text { Pregnant } \\
\text { cows }\end{array}$ & $\begin{array}{l}\text { Cumulative } \\
\text { total }\end{array}$ & $\begin{array}{l}\text { Unknown/ } \\
\text { open cows }\end{array}$ & $\begin{array}{l}\text { Cumulative } \\
\text { total }\end{array}$ & Calculation & $C R_{n}$ \\
\hline 1 & 50 & 108 & 36 & 98 & $50 /(108+98-36)=$ & 0.294 \\
\hline 2 & 19 & 58 & 17 & 62 & $19 /(58+62-17)=$ & 0.184 \\
\hline 4 & 11 & 21 & 8 & 32 & $11 /(21+32-8)=$ & 0.244 \\
\hline 5 & 4 & 10 & 5 & 24 & $4 /(10+24-5)=$ & 0.138 \\
\hline 6 & 0 & 6 & 10 & 19 & $0 /(6+19-10)=$ & 0.000 \\
\hline $10+$ & 0 & & 2 & & & \\
\hline Total cows & 108 & & 98 & & & \\
\hline $\begin{array}{l}\text { Total inseminations } \\
\text { CR for all services (CRall) }\end{array}$ & 249 & & 279 & & $108 /(249+279-98)=$ & 0.251 \\
\hline
\end{tabular}

${ }^{1} C R_{n}=$ conception rate for the $n$th service, calculated as pregnant cows divided by the sum of pregnant cows plus open/unknown cows minus the open/unknown cows at the $n$th service. Cumulative total $=$ cumulative number of cows from the nth service to the $10+$ service for pregnant and for unknown/open cows.

10 to $17 \mathrm{~d}$ (a1017), 18 to $24 \mathrm{~d}$ (a1824), 25 to $35 \mathrm{~d}$ (a2535), 36 to $48 \mathrm{~d}$ (a3648), and $>48 \mathrm{~d}$ (a49). This provided an evaluation of reinsemination management and was used to estimate postinsemination insemination efficiency (RPTIR), as $\left[1-(\mathrm{a} 49)^{0.5}\right]$. This was based on 2 opportunities to detect estrus at 18 to $24 \mathrm{~d}$ and at 36 to $48 \mathrm{~d}$ postinsemination and accounted for TAI resynchronization programs that skew reinseminations to BI greater than a1824. Average days between inseminations (BI) was calculated for days from first to second insemination and each succeeding insemination up to 4 inseminations.

Conception rate was calculated from the XsysC adjusted records (step 5, Table 2). Cows confirmed pregnant and not confirmed pregnant for $\mathrm{Xsys}_{\mathrm{C}}$ were distributed by number of services. Cows confirmed pregnant had known outcomes for CR analysis, whereas cows with unknown outcomes had censored outcomes for last insemination. Cows with unknown outcome at the last service and cows confirmed open were both treated as unknown status. Conception rate for each service was calculated as follows:

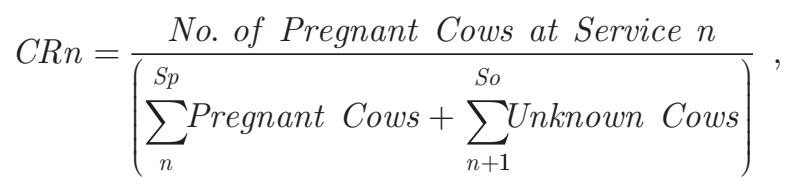

where $n=$ service number $(1,2,3, \ldots), S p=$ maximal service number for pregnant cows, and $S o=$ maximal service number for open (unknown) cows

See Table 3 for an example of calculation of conception rate for each service number. Conception rate was calculated for each service number (FSTCR for first service) and across all services (CRall):

$$
\text { CRall }=\text { total pregnant cows } / \text { (total services }
$$

in pregnant cows + total services in unknown cows

$$
\text { - number of unknown cows). }
$$

In step 6, PR was calculated by distributing cows based on DIM at last insemination by $21-\mathrm{d}$ categories from the oVWP using the XsysC reproductive data. Cows were categorized within each 21-d period as pregnant or not confirmed pregnant. Cows not confirmed pregnant were those with open or unknown insemination codes. An actuarial method was used to calculate PR for each 21-d period based on cumulative totals from the interval of interest (Rosner, 2006). The PR within each 21-d period represents a hazard of pregnancy within the interval. Cows with unknown outcome were censored at the beginning of the interval for the calculation. An overall PR was calculated by using a weighted averaging for eight 21-d intervals following the oVWP. The proportion pregnant within each 21-d interval was used to calculate a survival curve of pregnancy by time postcalving from the oVWP.

In step 7, economic values were assigned to each 21 -d interval from the oVWP based on a fixed marginal milk price $(\$ 0.10 / \mathrm{lb}$, using a feed cost value of $\$ 0.04$ per unit of milk yield and a milk price of $\$ 0.14 / \mathrm{lb}$ ), calf value $(\$ 100)$, cull cow value $(\$ 500)$, and replacement heifer value $(\$ 1,200)$. Economic values were calculated by difference from a targeted PR of $25 \%$. The value for the reproductive program was estimated as the weighted sum of the marginal proportion of pregnant cows in each 21-d period multiplied by the economic value within each interval. The slope of the pregnancy value by DIM estimated the value of a day open, which was $\$ 2.29 / \mathrm{d}$ for these input values. 
Steps 7, 8, and 9 analyzed oVWP, IR (FSTIR and RPTIR), CR, and PR for parity groups 1,2 , and 3 and greater and for season of calving and season of first insemination (seasons as follows: winter (December through February), spring (March through May), summer (June through August), and fall (September through November). Step 10 analyzed culling by reason and by DIM when cows left the herd.

Pearson correlation statistics were examined for relationships between reproductive summary statistics for the 16 herds and the reported VWP (rVWP) from the farm survey and the oVWP using Proc Corr in SAS software (version 9.2, SAS Institute Inc., Cary, NC). The standard error of a proportion (SEP) was calculated for proportion summary statistics and used to describe the $95 \%$ confidence limit around each herd mean. The number of observations for use in the denominator was active cows for CR and IR estimates and available cows for the BI categories. Herd differences for proportional statistics were based on nonoverlapping ranges for the 95\% confidence limit.

Summary statistics for FSTIR, RPTIR, FSTCR, CRall, PR, oVWP, and value, along with the appropriate SEP, were compiled in a data set by herd. Unadjusted and unweighted means and standard deviations were calculated for each summary statistic across the herds. The oVWP was used to classify herds by oVWP: $<60 \mathrm{~d}$ (VWP50), 60 to $69 \mathrm{~d}$ (VWP60), and 70 to 80d (VWP70). Herds were classified based on major breed as Holstein (10 herds), mixed Holstein (3 herds), and mixed Jersey or Jersey (3 herds). Statistical differences for DFS, FSTIR, RPTIR, FSTCR, CRall, PR, and value for oVWP class and breed were examined using PROC GLM in SAS software (version 9.2, SAS Institute Inc.) weighted by the inverse of the appropriate SEP multiplied by $1 /$ number $^{0.5}$ for the proportional indices. For oVWP, DFS, BI, and value, the inverse of the SEP of FSTIR, RPTIR, and PR multiplied by $1 /$ number $^{0.5}$, respectively, were used as weighting variables for statistical comparison of VWP class and breed groups. For comparison, summary records for reproduction from herds subscribing to DRMS are presented in Table 1 (Raleigh DRMS, 2012).

\section{RESULTS}

Table 4 presents a summary of herd management practices used by the 16 farms. This information was obtained from the detailed survey (available at http:// www.dcrcouncil.org/reproduction-awards.aspx) completed by the farm managers. Herds ranged in size from 226 to 6,126 cows (Table 4). Holstein cows were the dominant breed; 10 farms were entirely Holstein breed, 1 herd was Jersey breed, and 5 herds reported mixed breeds ( 3 primarily Holstein mix and 2 primarily Jersey mix). Housing was freestall barns in all herds (2 herds not reporting). The rVWP ranged from 50 to $71 \mathrm{~d}$. All but 1 herd reported using TAI for first insemination and all but 2 herds reported using TAI for repeat insemination (2 herds not reporting).

Clean-up bulls were reported to be used on 4 of the herds (Table 4). The proportion of inseminations performed on observed estrus was estimated on the herd surveys by farm managers and ranged from 21 to $100 \%$ of inseminations (Table 4). Eleven of the 14 farms that completed the survey reported using heat detection aids, the most common being tail-head chalk or paint (Table 4). Two herds reported using pedometers and 3 farms reported they only used visual observation of estrus behavior with no secondary aids.

Farms used from 1 to 5 inseminators, with a modal frequency of 2 (Table 4). Seven farms used inseminator services from nonfarm employees, whereas 6 farms reported using only farm employees for inseminations, and 1 farm reported using both farm and nonfarm employees for inseminations (Table 4; 2 farms not reporting information). The number of semen straws thawed at one time was typically fewer than 5 , with 1 farm reporting 8 straws thawed at one time (Table 4). Reproductive examinations were performed weekly (7 herds) or every 2 wk (7 herds), with 2 herds not reporting information (Table 4). Method of pregnancy diagnosis was by rectal exam on 4 herds and by ultrasound imagining per rectum on 10 herds (Table 4). The earliest days postinsemination for first pregnancy examination was $27 \mathrm{~d}$ and the latest was $40 \mathrm{~d}$, with the modal frequency at $28 \mathrm{~d}$ for ultrasound and 35 to 40 d for rectal palpation (Table 4). Re-exams were performed 2 or 3 times on pregnant cows from 53 to $200 \mathrm{~d}$ after last insemination and again at dry-off (Table 4).

Table 5 provides an analysis of reproductive records from the herds. The oVWP ranged from 50 to $73 \mathrm{~d}$ across all herds, with a mean of $60.0 \mathrm{~d}$ (SD $8.9 \mathrm{~d}$; Table 5 ). The mean oVWP was similar to the mean rVWP $(62.7 \mathrm{~d}$, SD $8.6 \mathrm{~d})$. The correlation between oVWP and rVWP was $0.88(P<0.0001)$. Mean DFS ranged from 63 to $78 \mathrm{~d}$ with a mean of $71.2 \mathrm{~d}(\mathrm{SD} 4.7 \mathrm{~d})$ and was highly correlated with both oVWP $(\mathrm{r}=0.73, P$ $<0.001)$ and $\operatorname{rVWP}(\mathrm{r}=0.73, P<0.003$; Table 5). This compares to a mean DFS of $91.7 \mathrm{~d}$ in DHIA data (Table 1) and ranked these herds in the bottom 18.6 percentile of herds.

First insemination intensity, measured as the proportion of cows inseminated within 21-d periods from the oVWP, ranged from 74.5 to $99.8 \%$, with 7 herds having FSTIR $>90 \%, 2$ herds between 80 and $90 \%$, and 7 herds ranging from 74.5 to $78.6 \%$ (Table 5 ). The mean FSTIR was $85.9 \%$ (SD 10.2\%; Table 5). The insemination rate 
Table 4. Herd reproductive management practices ${ }^{1}$ based on a survey of 16 herds with excellent reproductive performance selected for Dairy Cattle Reproductive Council award ${ }^{1}$

\begin{tabular}{|c|c|c|c|c|c|c|c|c|c|c|c|c|c|c|c|c|c|c|c|}
\hline \multirow[b]{2}{*}{ Herd } & \multirow[b]{2}{*}{ Breed $^{2}$} & \multirow[b]{2}{*}{ No. ${ }^{3}$} & \multirow{2}{*}{$\begin{array}{l}\mathrm{RHA}^{4}{ }^{4} \\
\mathrm{lb}\end{array}$} & \multirow[b]{2}{*}{ House $^{5}$} & \multirow{2}{*}{$\underset{\mathrm{d}}{\mathrm{rVWP}}{ }^{6}$} & \multicolumn{2}{|c|}{$\mathrm{TAI}^{7}$} & \multirow{2}{*}{$\begin{array}{l}\text { Nat. } \\
\text { bull }^{8}\end{array}$} & \multicolumn{2}{|c|}{ Estrus detection ${ }^{9}$} & \multicolumn{3}{|c|}{ Insemination $^{10}$} & \multicolumn{4}{|c|}{ Pregnancy exam ${ }^{11}$} & \multirow{2}{*}{$\begin{array}{l}\text { Cull, }^{12} \\
\text { No. }\end{array}$} & \multirow{2}{*}{$\begin{array}{l}\mathrm{RC}^{13} \\
\text { No. }\end{array}$} \\
\hline & & & & & & Pre & $\operatorname{Re}$ & & $\% \mathrm{AI}$ & Aids & No. & Who & Straw & Freq. & Meth. & Days & ReChk & & \\
\hline 1 & $\mathrm{H}$ & 1,158 & 28,145 & FS & 67 & $\mathrm{Y}$ & $\mathrm{Y}$ & $\mathrm{N}$ & 44 & Chalk & 2 & Frm & 3 & $\mathrm{~W}$ & $\mathrm{R}$ & 37 & 95 & 372 & 20 \\
\hline 2 & $0.97 \mathrm{H}$ & 663 & 23,428 & FS & 70 & Y & $\mathrm{Y}$ & Y & 21 & Chalk & 4 & Off & 5 & W & $\mathrm{U}$ & 39 & $63 / 183$ & 187 & 9 \\
\hline 3 & $0.90 \mathrm{~J}$ & 1,194 & 22,600 & FS & 55 & Y & $\mathrm{Y}$ & $\mathrm{N}$ & 63 & Ped & 3 & Frm & $2-5$ & B & $\mathrm{U}$ & 29 & $53 / 75 / \mathrm{d}$ & 402 & 51 \\
\hline 4 & $\mathrm{H}$ & 2,973 & 29,500 & FS & 71 & $\mathrm{Y}$ & $\mathrm{Y}$ & $\mathrm{N}$ & 47 & Vis & 5 & Frm & 2 & $\mathrm{~W}$ & $\mathrm{R}$ & 40 & 150 & 958 & 150 \\
\hline 5 & $\mathrm{H}$ & 442 & 26,651 & FS & 68 & $\mathrm{Y}$ & $\mathrm{Y}$ & Y & 98 & Ped & 1 & Frm & 2 & B & $\mathrm{U}$ & 28 & $>60$ & 137 & 17 \\
\hline 6 & $\mathrm{H}$ & 393 & 26,564 & FS & 60 & $\mathrm{Y}$ & $\mathrm{Y}$ & $\mathrm{N}$ & 40 & Chalk & 2 & Off & $1-5$ & B & $\mathrm{U}$ & 28 & $70 / \mathrm{d}$ & 180 & 16 \\
\hline 7 & $0.36 \mathrm{H}$ & 262 & 21,841 & FS & 74 & $\mathrm{Y}$ & $\mathrm{Y}$ & $\mathrm{N}$ & 36 & Vis & 2 & Off & $1-6$ & $\mathrm{~B}$ & $\mathrm{U}$ & 28 & 64 & 112 & 4 \\
\hline 8 & $\mathrm{H}$ & 1,427 & 28,900 & FS & 50 & $\mathrm{Y}$ & $\mathrm{Y}$ & Y & 89 & Vis & 5 & Both & 2 & W & $\mathrm{U}$ & 35 & $\mathrm{D}$ & 511 & 127 \\
\hline 9 & $0.25 \mathrm{H}$ & 899 & 23,200 & FS & 69 & $\mathrm{Y}$ & $\mathrm{Y}$ & $\mathrm{N}$ & 28 & Chalk & 3 & Off & $<5$ & $\mathrm{~W}$ & $\mathrm{U}$ & 27 & $67 / 200$ & 205 & 15 \\
\hline 10 & $\mathrm{H}$ & 1,539 & 26,210 & FS & 50 & $\mathrm{Y}$ & $\mathrm{Y}$ & $\mathrm{N}$ & 94 & Chalk & 2 & Frm & $<4$ & B & $\mathrm{R}$ & 36 & 189 & 589 & 26 \\
\hline 11 & $\mathrm{H}$ & 2,253 & 23,106 & NA & NA & NA & NA & NA & NA & NA & $\mathrm{NA}$ & NA & NA & NA & NA & NA & NA & 770 & NA \\
\hline 12 & $\mathrm{H}$ & 6.126 & 26,542 & NA & NA & $\mathrm{NA}$ & NA & $\mathrm{NA}$ & NA & NA & $\mathrm{NA}$ & $\mathrm{NA}$ & NA & $\mathrm{NA}$ & NA & $\mathrm{NA}$ & $\mathrm{NA}$ & NA & NA \\
\hline 13 & $\mathrm{~J}$ & 1,050 & 18,194 & FS & 65 & Y & $\mathrm{Y}$ & $\mathrm{N}$ & 41 & Chalk & 1 & Off & 8 & B & $\mathrm{U}$ & 27 & 76 & 464 & 52 \\
\hline 14 & $\mathrm{H}$ & 590 & 28,098 & FS & 70 & Y & $\mathrm{Y}$ & $\mathrm{N}$ & 37 & Chalk & 5 & Off & 4 & $\mathrm{~W}$ & $\mathrm{U}$ & 32 & 60 & 152 & 7 \\
\hline 15 & $\mathrm{H}$ & 2.290 & 28,268 & FS & 60 & $\mathrm{Y}$ & $\mathrm{Y}$ & $\mathrm{N}$ & 65 & Chalk & 2 & Off & 5 & $\mathrm{~W}$ & $\mathrm{U}$ & 37 & $57 / 195$ & 503 & 68 \\
\hline 16 & $0.70 \mathrm{~J}$ & 3,205 & 19,907 & FS & 50 & $\mathrm{~N}$ & $\mathrm{~N}$ & Y & 100 & Chalk & 2 & Frm & NA & B & $\mathrm{R}$ & 35 & 215 & 199 & 25 \\
\hline
\end{tabular}

${ }^{1} \mathrm{NA}=$ not applicable (data survey not completed).

${ }^{2}$ Breed $=$ proportion of major breed in herd; $\mathrm{H}=$ Holstein $(100 \%) ; \mathrm{J}=$ Jersey $(100 \%) ; 0.97 \mathrm{H}=97 \%$ of cows Holstein; 0.90J = 90\% of cows Jersey; 0.36H $=36 \%$ of cows Holstein, $44 \%$ of cows Jersey, $6 \%$ of cows Brown Swiss, $14 \%$ of cows crosses; $0.25 \mathrm{H}=25 \%$ of cows Holstein, $75 \%$ of cows various breed crosses; $0.70 \mathrm{~J}=70 \%$ of cows Jersey, $20 \%$ of cows Jersey/Holstein crosses, $10 \%$ of cows Holstein.

${ }^{3}$ No. $=$ number of lactating and dry cows in herd.

${ }^{4} \mathrm{RHA}=$ rolling herd average or average 305-d milk yield, lb/cow per year.

${ }^{5} \mathrm{FS}=$ freestall barn housing.

${ }^{6} \mathrm{rVWP}=$ reported voluntary waiting period by herd manager.

${ }^{7} \mathrm{TAI}=$ timed AI; Pre = synchronization program for first insemination (yes, Y, or no, N); Re = herd survey reports using a synchronization program for repeat insemination (yes, $\mathrm{Y}$, or no, N).

$\stackrel{8}{8}$ Nat. bulls $=$ natural service bulls $($ yes, $\mathrm{Y}$, or no, $\mathrm{N})$

矛 $9 \% \mathrm{AI}=$ percentage of inseminations performed based on estrus detection for all inseminations; Aids = estrus detection aids used $($ Chalk $=$ crayon stick mark over tail head as secondary aid; Ped = pedometer activity monitor used for estrus detection aid; Vis = visual observation of estrus activity).

of ${ }^{10} \mathrm{No}=$ number of inseminators; Who: Frm = farm employees as inseminators; Off = inseminators employed by AI industry; Straw $=$ number of straws of semen thawed at a time 紊. for insemination.

( ${ }^{11}$ Pregnancy exam = pregnancy examination procedures identified in management survey; Freq. $=$ frequency $(\mathrm{W}=$ weekly, $\mathrm{B}=$ biweekly $) ;$ Meth. $=$ method $(\mathrm{R}=$ rectal palpation ก. $\mathrm{U}=$ ultrasound); Days = earliest days postinsemination of pregnancy examination; ReChk = recheck, days postinsemination of re-examination for pregnancy in pregnant cows; D $=$ at dry off.

${ }^{12}$ Total number of culls.

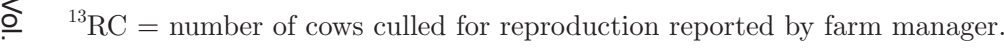


Table 5. Herd means for selected reproductive parameters based on a survey of 16 herds with excellent reproductive performance selected for Dairy Cattle Reproductive Council award

\begin{tabular}{|c|c|c|c|c|c|c|c|c|c|c|c|c|c|c|c|}
\hline \multirow[b]{2}{*}{ Herd } & \multirow[b]{2}{*}{$\begin{array}{c}\text { Active } \\
\text { cows, }{ }^{1} \text { No. }\end{array}$} & \multirow[b]{2}{*}{$\begin{array}{c}\text { oVWP, } \\
\mathrm{d}\end{array}$} & \multirow[b]{2}{*}{$\begin{array}{c}\mathrm{DFS}^{3}{ }^{3} \\
\mathrm{~d}\end{array}$} & \multirow[b]{2}{*}{$\underset{\%}{\operatorname{FST~IR},}{ }^{4}$} & \multirow[b]{2}{*}{$\begin{array}{c}\mathrm{INT},{ }^{5} \\
\mathrm{~d}\end{array}$} & \multicolumn{6}{|c|}{ RPTIR $^{6} \%$} & \multirow[b]{2}{*}{$\begin{array}{c}\text { FSTCR }^{7} \\
\%\end{array}$} & \multirow[b]{2}{*}{$\underset{\%}{\text { CRall, }^{8}}$} & \multirow[b]{2}{*}{$\begin{array}{c}\mathrm{PR},{ }^{9} \\
\%\end{array}$} & \multirow[b]{2}{*}{$\underset{\%}{\text { Cull, }^{10}}$} \\
\hline & & & & & & $<10 \mathrm{~d}$ & $10-17 \mathrm{~d}$ & $18-24 \mathrm{~d}$ & $25-35 \mathrm{~d}$ & $36-48 d$ & $>48 \mathrm{~d}$ & & & & \\
\hline 1 & 1,158 & 54 & 69 & 93.8 & 32.5 & 6.6 & 6.3 & 27.0 & 15.2 & 36.4 & 8.6 & 37.5 & 33.3 & 28.0 & 37.1 \\
\hline 2 & 663 & 72 & 78 & 97.6 & 39.0 & 2.0 & 5.6 & 26.5 & 7.2 & 44.5 & 14.3 & 47.4 & 41.6 & 35.9 & 24.3 \\
\hline 3 & 1,194 & 50 & 70 & 74.5 & 30.8 & 8.2 & 4.1 & 35.9 & 16.4 & 26.5 & 8.9 & 50.1 & 43.9 & 30.4 & 33.2 \\
\hline 4 & 2,973 & 70 & 74 & 99.6 & 32.6 & 5.5 & 6.3 & 41.7 & 16.3 & 9.7 & 20.5 & 45.4 & 35.0 & 34.0 & 29.7 \\
\hline 5 & 442 & 61 & 75 & 78.6 & 38.0 & 3.7 & 7.1 & 31.8 & 19.9 & 16.6 & 20.9 & 50.9 & 42.3 & 32.8 & 26.9 \\
\hline 6 & 393 & 54 & 70 & 82.7 & 32.6 & 5.9 & 4.3 & 32.3 & 16.6 & 25.2 & 15.8 & 42.6 & 37.6 & 29.6 & 43.7 \\
\hline 7 & 262 & 73 & 77 & 99.5 & 36.4 & 1.5 & 4.1 & 28.9 & 17.0 & 28.4 & 20.1 & 49.8 & 40.1 & 38.3 & 49.0 \\
\hline 8 & 1,427 & 50 & 64 & 76.5 & 35.4 & 1.6 & 2.9 & 41.8 & 17.2 & 20.7 & 15.8 & 42.2 & 39.6 & 30.0 & 26.5 \\
\hline 9 & 899 & 68 & 72 & 98.5 & 32.6 & 11.1 & 4.5 & 28.3 & 7.4 & 41.0 & 7.7 & 41.9 & 39.6 & 34.1 & 28.5 \\
\hline 10 & 1,539 & 50 & 65 & 76.5 & 27.1 & 20.8 & 4.5 & 31.0 & 15.8 & 15.6 & 12.2 & 40.6 & 34.9 & 27.3 & 50.1 \\
\hline 11 & 2,253 & 55 & 74 & 75.4 & 36.2 & 3.1 & 4.8 & 36.5 & 15.7 & 14.5 & 25.3 & 40.4 & 37.2 & 26.5 & 40.6 \\
\hline 12 & 6,126 & 52 & 63 & 85.6 & 31.9 & 7.2 & 5.5 & 41.4 & 14.6 & 11.8 & 19.5 & 39.6 & 35.4 & 28.6 & 13.0 \\
\hline 13 & 1,050 & 69 & 73 & 98.5 & 29.9 & 5.0 & 7.5 & 36.5 & 21.5 & 19.5 & 10.1 & 48.7 & 42.8 & 39.4 & 33.1 \\
\hline 14 & 590 & 70 & 75 & 99.8 & 35.1 & 1.5 & 4.5 & 35.6 & 13.1 & 32.8 & 12.5 & 38.1 & 36.8 & 30.6 & 23.2 \\
\hline 15 & 2,290 & 61 & 74 & 76.6 & 33.1 & 2.3 & 4.5 & 42.0 & 15.3 & 23.6 & 12.4 & 43.7 & 40.0 & 30.4 & 29.6 \\
\hline 16 & 3,205 & 51 & 66 & 76.5 & 31.6 & 0.4 & 4.5 & 55.2 & 17.0 & 12.3 & 10.7 & 51.8 & 44.7 & 35.9 & 25.6 \\
\hline Mean & 1,654 & 60.0 & 71.2 & 85.9 & 33.4 & 5.4 & 5.1 & 35.8 & 15.4 & 23.7 & 14.7 & 44.4 & 39.1 & 32.0 & 32.1 \\
\hline SD & 1,494 & 8.9 & 4.7 & 10.2 & 3.1 & 5.0 & 1.2 & 7.5 & 3.7 & 10.7 & 5.2 & 4.8 & 3.5 & 3.9 & 9.9 \\
\hline
\end{tabular}

${ }^{1}$ Active cows = lactating and dry cows in herd at the date of reproductive data analysis adjusted for cows calving in the calendar period January 1 to December $31,2010$.

${ }^{2}$ oVWP $=$ observed voluntary waiting period based on $5 \%$ of first inseminations or least days to first insemination.

${ }^{3} \mathrm{DFS}=$ days to first service

${ }^{4} \mathrm{FST}$ IR $=$ first insemination rate based on distribution of first inseminations in 21-d periods from the oVWP.

${ }^{5} \mathrm{INT}=$ mean days between first and second service.

${ }^{6} \mathrm{RPTIR}=$ repeat insemination rate, estimated as $\left(1-\right.$ the proportion of insemination intervals $\left.>49 \mathrm{~d}^{0.5}\right)$.

${ }^{7} \mathrm{FSTCR}=$ conception rate at first insemination.

${ }^{8} \mathrm{CRall}=$ conception rate across all inseminations.

${ }^{9} \mathrm{PR}=$ pregnancy rate

${ }^{10} \mathrm{Cull}=$ percentage of cows culled calculated as number of animals removed from the herd in a year divided by animals calving within a year period 
for repeat insemination estimated from re-insemination patterns ranged from 49.7 to $79.9 \%$ (Table 5), and the mean across all herds was $63.2 \%$ (SD 8.0\%). The BI was $<40 \mathrm{~d}$ for all herds but greater than $30 \mathrm{~d}$ on all but one herd, and the overall mean was $33.4 \mathrm{~d}$ (SD 3.1 d; Table 5). Heersche and Nebel (1994) suggested that RPTIR could be estimated as 21 divided by the mean interval; using this method, RPTIR was estimated as $62.9 \%$, similar to the estimate using the method in this paper. The BI was positively correlated with a49 $(\mathrm{r}=$ $0.51, P<0.04$ ), indicating that longer average days between inseminations was associated with more long intervals.

The mean PR across all herds was $32.0 \%$ (SD 3.9\%) and ranged from 26.5 to $39.4 \%$ (Table 5). This compares to a mean PR of $15.9 \%$ in the DHIA data (Table $1)$. The mean PR for these herds placed them in the 99th percentile of herds based on the DHIA data in Table 1. The CRall for herds ranged from 33.3 to $44.7 \%$ and the mean across all herds was 39.1\% (SD 3.5\%; Table 5). First-service CR in DHIA data was reported to be $43.1 \%$ (Table 1), similar to mean FSTCR in these herds (44.1\%, Table 6), which would rank them in the 50th percentile of herds in the Raleigh database. Pregnancy rate in the herds was significantly correlated with FSTCR $(\mathrm{r}=0.72, P<0.002)$, with CRall $(\mathrm{r}=$
$0.69, P<0.003)$, with FSTIR $(\mathrm{r}=0.55, P<0.026)$, but not with RPTIR ( $\mathrm{r}=0.27, P<0.32)$.

The proportion of repeat inseminations within each day category is presented in Table 5. The herds clustered in 3 groups based on the proportion of inseminations in a10 (Table 5). Two herds had a significantly greater proportion of cows in a10 (11.1 and 20.8\% of all repeat inseminations; Table 5). Five herds ranged from 5.0 to $8.2 \%$ of repeat inseminations in a10, and 7 herds had 0.4 to $3.1 \%$ of repeat inseminations in a10. Typically, the proportions of inseminations observed in a10 for a herd are 5\% or less (personal observation). Physiologically, no estrus events should be less than 10 $\mathrm{d}$ apart. Inseminations occurring at this frequency may due to inseminations $1 \mathrm{~d}$ apart, which are sometimes used for TAI following a prostaglandin-induced estrus or occur between 2 and 9d apart, suggesting an insemination of cows not truly in estrus. Herds with the lowest proportion of a10 inseminations reported using chalk, pedometers, or visual estrus detection methods, which were similar to aids reportedly used in herds with higher proportions of a10 inseminations, so there was no clear distinction of estrus detection method with low or high proportion of a10 repeat inseminations (Tables 4 and 5).

Repeat inseminations classified as a1017 were less than $10 \%$ of repeat intervals for all herds and ranged

Table 6. Herd programs to control first insemination as reported by herd managers from a survey of practices ${ }^{1}$

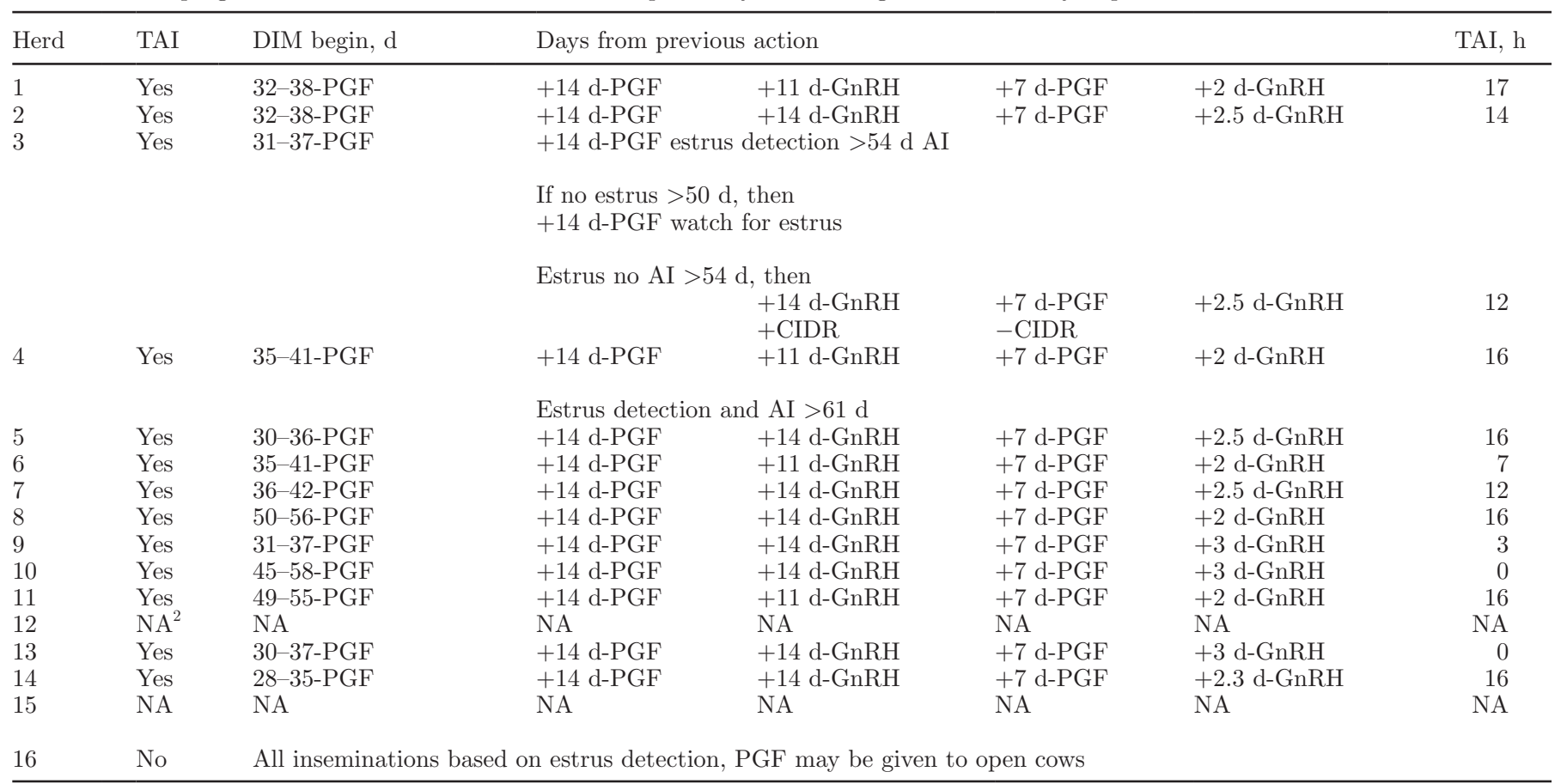

${ }^{1} \mathrm{PGF}=$ prostaglandin $\mathrm{F}_{2 \alpha} ; \mathrm{TAI}=$ timed $\mathrm{AI}, \mathrm{h}=$ hours from prior $\mathrm{GnRH}$ injection; $\mathrm{CIDR}=$ controlled intravaginal drug releasing device, contains progesterone; + CIDR $=$ insertion of CIDR; - CIDR $=$ removal of CIDR.

${ }^{2}$ Not applicable. 
from 2.9 to $7.5 \%$ across herds (Table 5 ). Inseminations in this interval may be due to estrus detection errors or due to physiological short inter-estrus intervals. Typically, the proportion of a1017 inseminations is less than $10 \%$ in a herd (personal observation). Repeat inseminations classified as a1824, one inter-estrus interval, varied considerably across the herds; these usually suggest the intensity of estrus detection used to control reinsemination (Table 5). The greatest proportion of inseminations occurring in one estrus interval was $55.0 \%$ in a herd that reported using $100 \%$ estrus detection for inseminations (herd 16; Tables 4 and 5). Four herds varied from 42.0 to $41.4 \%$ (Table 5 ); 7 herds had proportions of a1824 re-insemination from 31.0 to $36.5 \%$ (Table 5); the remaining 4 herds had proportions of a1824 re-insemination from 26.5 to $28.9 \%$ of inseminations. The greater the proportion of cows inseminated in a1824, the smaller the proportion of re-inseminations in a3648 ( $\mathrm{r}=-0.67, P<0.001)$.

The proportion of re-inseminations in a2535 was less than $10 \%$ in only 2 herds (Table 5), between 13.2 and $19.9 \%$ in 13 herds, and $21.5 \%$ in 1 herd. Inseminations in a2535 d may be due to errors of insemination or due to an extended inter-estrus interval caused by embryonic deaths occurring after $15 \mathrm{~d}$ postfertilization. In addition, some resynchronization programs that are based on ultrasound examination for pregnancy and ovarian structures at 26 to $30 \mathrm{~d}$ postinsemination may increase a2535 inseminations due to inseminations following prostaglandin-induced estruses within this period. Typically, the proportion of inseminations observed in a2535 is less than $15 \%$ of re-inseminations (personal observation).

Re-inseminations classified as a3648 represent one missed estrus, an extended inter-estrus interval associated with embryonic death, or a resynchronization program using Ovsynch initiated between 26 and $38 \mathrm{~d}$ postinsemination. In all but one herd a3648 inseminations were above $10 \%$ of re-inseminations. We observed a wide range in proportion of re-inseminations in a3648 from 11.8 to $44.5 \%$ (Table 5). Frequency of examination of pregnancy did not influence the proportion of a3648. All but 2 herds reported using TAI programs for reinsemination, but we found a great deal of variation in time of deployment. The proportion of a1824 inseminations negatively correlated with the proportion of a3648 inseminations $(\mathrm{r}=-0.67, P<004)$. This suggests that herds using more TAI to control re-insemination used less intense estrus detection programs. Frequency of veterinary examination and days postinsemination for pregnancy examination did not influence a3648.

Proportion of re-inseminations classified as a49 ranged from 7.7 to $25.3 \%$ (Table 5 ). The proportion of inseminations classified as a49 was negatively correlated with RPTIR $(\mathrm{r}=-0.83, P<0.001)$ and with a3648 re-inseminations $(\mathrm{r}=-0.49, P<0.05)$, but had no significant correlation with a1824 inseminations (r $=0.06, P<82$ ). This suggested that a49 inseminations increased from herd programs that used a TAI program that resulted in longer BI to re-insemination, not necessarily due to lower estrus detection. Herds that used veterinary examination after $38 \mathrm{~d}$ postinsemination to determine initiation of a resynchronization Ovsynch protocol would have TAI after $49 \mathrm{~d}$. Such intervals were possible in herds 3, 4, 10, and 13 (Table 7).

Conception rate across all inseminations (Table 5) ranged from 33.3 to $44.7 \%$ for the 16 herds, and 7 herds had CRall $>40 \%$. Conception rate across all inseminations was correlated with PR $(\mathrm{r}=0.70, P<0.003)$ and with FSTCR $(\mathrm{r}=0.88, P<0.001)$. Cull rates ranged from 13.0 to $50.1 \%$, a wide range (Table 5 ). Mean cull rate was $32.1 \%$ and was similar to those reported for herds in DHIA data (Table 1).

Table 6 and Table 7 outline herd programs for first insemination (Table 6) and repeat insemination (Table 7 ). All but one herd that filled out the herd management survey used a TAI program for first insemination (Table 6). All herds using TAI for first insemination used a Presynch Ovsynch program, initiating an Ovsynch TAI following 2 injections of prostaglandin (PGF) 14 d apart (Table 6). Nine herds initiated a PGF sequence between 30 and 40 DIM, 2 herds after 40 DIM, and 1 herd before 30 DIM (Table 6). Four herds initiated the Ovsynch protocol $11 \mathrm{~d}$ following the second PGF injection, and 8 herds began the Ovsynch protocol 14 $\mathrm{d}$ following the second PGF injection (Table 6). One herd varied the Ovsynch sequence by incorporating an additional PGF injection or by following an Ovsynch protocol combined with insertion of a continuous intravaginal drug releasing device (CIDR) depending upon prior observation of estrus (herd 3, Table 6).

The GnRH injection before TAI varied as did the time (h) to TAI following the $\mathrm{GnRH}$ injection before insemination (Table 6). Ten herds gave GnRH approximately $2 \mathrm{~d}$ following PGF and inseminated cows 7 to 16 $\mathrm{h}$ following the GnRH injection. Two herds gave GnRH $3 \mathrm{~d}$ following a PGF injection in the Ovsynch protocol and inseminated cows at the time of the GnRH injection (Table 6). One herd reported only using heat detection for all inseminations (herd 16, Table 6) with occasional PGF injection followed by estrus observation in nonpregnant cows. We observed no association of FSTCR with GnRH given at 11 or $14 \mathrm{~d}$ following PGF or with time to TAI following GnRH in these herds. However, herd differences in CR would mask any difference in time to GnRH injection following PGF or 
Table 7. Herd programs to control re-insemination as reported by herd managers in a survey ${ }^{1}$

\begin{tabular}{|c|c|c|c|c|c|c|c|}
\hline \multirow{2}{*}{$\frac{\text { Herd }}{1}$} & \multirow{2}{*}{$\begin{array}{l}\begin{array}{l}\text { Vet. } \\
\text { frequency }\end{array} \\
\text { Weekly }\end{array}$} & \multirow{2}{*}{$\begin{array}{l}\text { Preg. } \\
\mathrm{Dx}^{3}{ }^{3} \mathrm{~d}\end{array}$} & \multirow{2}{*}{$\begin{array}{l}\begin{array}{l}\text { Preg. } \\
\text { method }^{4}\end{array} \\
\text { Palpation }\end{array}$} & \multicolumn{4}{|c|}{ Treatment $^{5}$} \\
\hline & & & & $\frac{\mathrm{d}-\mathrm{trt}}{+30-36-\mathrm{GnRH}}$ & $+7 \mathrm{~d}-\mathrm{PGF}$ & $+2 \mathrm{~d}-\mathrm{GnRH}$ & $+16 \mathrm{~h}$ TAI \\
\hline \multirow[t]{3}{*}{3} & \multirow[t]{3}{*}{ Biweekly } & \multirow[t]{3}{*}{$29-42$} & \multirow[t]{3}{*}{ US } & $\geq 36 \mathrm{~d}$ & +0 d-PGF & detection $11 \mathrm{~d}$ & \\
\hline & & & & $\overline{32}-35 \mathrm{~d}-\mathrm{GnRH}$ & $+7 \mathrm{~d}-\mathrm{PGF}$ & $+2 \mathrm{~d}-\mathrm{GnRH}$ & $+16 \mathrm{~h}$ TAI \\
\hline & & & & $\geq 50 \mathrm{~d}-\mathrm{GnRH}$ & $+7 \mathrm{~d}-\mathrm{PGF}$ & $+2 \mathrm{~d}-\mathrm{GnRH}$ & $+16 \mathrm{~h}$ TAI \\
\hline 5 & Biweekly & $28-44$ & US & 28-34 d-GnRH & $+7 \mathrm{~d}-\mathrm{PGF}$ & $+2 \mathrm{~d}-\mathrm{GnRH}$ & $+16 \mathrm{~h}$ TAI \\
\hline 6 & Biweekly & $28-32$ & US & 28-32 d-GnRH & $+7 \mathrm{~d}-\mathrm{PGF}$ & $+2 \mathrm{~d}-\mathrm{GnRH}$ & $+7 \mathrm{~h}$ TAI \\
\hline \multirow[t]{3}{*}{7} & \multirow[t]{3}{*}{ Biweekly } & \multirow[t]{3}{*}{$28-42$} & US & \multicolumn{4}{|c|}{ 28-42 d-PGF estrus detection for AI } \\
\hline & & & or & $28-42 \mathrm{~d}-\mathrm{GnRH}$ & $+7 \mathrm{~d}-\mathrm{PGF}$ & $+2 \mathrm{~d}-\mathrm{GnRH}$ & $+16 \mathrm{~h}$ TAI \\
\hline & & & or & $\begin{array}{l}28-42 \mathrm{~d}-\mathrm{GnRH} \\
+ \text { CIDR }\end{array}$ & $\begin{array}{l}+7 \text { d-PGF } \\
- \text { CIDR }\end{array}$ & $+2 \mathrm{~d}-\mathrm{GnRH}$ & $+16 \mathrm{~h}$ TAI \\
\hline 8 & Weekly & $35-41$ & US & 35-41 d-PGF and estrus & ion for AI & & \\
\hline 12 & $\mathrm{NA}^{6}$ & NA & NA & $\mathrm{NA}$ & NA & NA & NA \\
\hline 13 & Biweekly & $27-41$ & US & $27-41 \mathrm{~d}-\mathrm{GnRH}$ & $+7 \mathrm{~d}-\mathrm{PGF}$ & $+3 \mathrm{~d}-\mathrm{GnRH}$ & $+0 \mathrm{~h}$ TAI \\
\hline 14 & Weekly & $32-38$ & US & $32-38 \mathrm{~d}-\mathrm{GnRH}$ & $+7 \mathrm{~d}-\mathrm{PGF}$ & $+2 \mathrm{~d}-\mathrm{GnRH}$ & $+8 \mathrm{~h}$ TAI \\
\hline 15 & NA & NA & NA & NA & $\mathrm{NA}$ & NA & NA \\
\hline 16 & Bimonthly & $35-49$ & Palpation & Estrus detection for AI & & & \\
\hline
\end{tabular}

${ }^{1} \mathrm{PGF}=$ prostaglandin $\mathrm{F}_{2 \alpha}$; TAI = timed $\mathrm{AI}, \mathrm{h}=$ hours from prior $\mathrm{GnRH}$ injection; CIDR = controlled intravaginal drug releasing device, contains progesterone; + CIDR $=$ insertion of CIDR; $-\mathrm{CIDR}=$ removal of CIDR .

${ }^{2}$ Vet. frequency $=$ frequency of veterinary visits for reproductive examination.

${ }^{3}$ Preg. Dx $=$ days following insemination of veterinary examination for pregnancy status.

${ }^{4}$ Preg. method $=$ method of examination by veterinarian of pregnancy status (US $=$ ultrasound).

${ }^{5}$ Treatment: d-trt = intervention administered at days following prior insemination based on either days following insemination (herds 1,2 ) or based on diagnosis of open status; treatment regimen was modified in some cases based on diagnosis of ovarian structures by the veterinarian; $\mathrm{d}$ or $\mathrm{h}$ following prior treatment $=$ days (or hours) from prior treatment for intervention.

${ }^{6}$ Not applicable.

time to insemination in this small data set. Of more importance is the consistency with which a herd can use the injection sequences and assign cows to the protocol.

Table 7 presents the reported herd programs to control re-insemination. These programs were more variable between farms than were first insemination programs as they were coordinated with veterinary visits for pregnancy examination. Two herds reported giving all cows $\mathrm{GnRH}$ at 30 to $36 \mathrm{~d}$ or at 32 to $38 \mathrm{~d}$ following insemination and before the veterinarian diagnosis of pregnancy or open status, which followed the GnRH injection by $7 \mathrm{~d}$ (herds 1 and 2, Table 7 ). If the veterinarian determined a cow was open, PGF was injected followed by a $\mathrm{GnRH}$ injection in $2 \mathrm{~d}$, which initiated a TAI in $16 \mathrm{~h}$ (herds 1 and 2, Table 7). In herds 4, 5, 6, 9,13 , and 14, cows diagnosed as nonpregnant at the time of the veterinary examination were injected with GnRH, which initiated an Ovsynch protocol for TAI (Table 7).

In herds 3,7 , and 10 , the veterinarian determined the appropriate resynchronization strategy in nonpregnant cows at time of examination based on ovarian structures or days following prior insemination. In general, in these herds, if a corpus luteum was determined to be present on one or both ovaries at time of examination, a PGF injection was given and cows were observed for estrus for re-insemination. If no corpus luteum was diagnosed on an ovary, GnRH was given and an Ovsynch protocol was initiated, with or without insertion of a CIDR (Table 7). Herd 3 modified the program based on days following prior insemination, injecting either PGF ( $>36$ or $<50 \mathrm{~d}$ following prior insemination) or GnRH (32 to $35 \mathrm{~d}$ following prior insemination) to initiate estrus detection or a TAI protocol (Table 7). In herd 10, a PGF injection was given to cows 36 to $50 \mathrm{~d}$ postinsemination if nonpregnant at examination, and insemination was based on observed estrus (Table 7). However, if cows were $>50 \mathrm{~d}$ from prior insemination, then an Ovsynch protocol was initiated with a CIDR treatment for TAI (Table 7).

In herd 8, open cows were injected with PGF and observed for estrus for re-insemination. In herds 11 
and 16, only estrus detection was used to re-inseminate open cows (Table 7). All herds reported using estrus detection before time of pregnancy diagnosis following insemination to control days between inseminations. Frequency of veterinary diagnosis (every week or every other week) was not associated with a difference in BI or any of the inter-breeding intervals, except that visits every other week were associated with a greater proportion of re-inseminations categorized as a2535, 18.7\% (SEM 2.0) compared with $13.2 \%$ (SEM 1.6) for herds reporting a weekly herd visit.

Figures 1 through 4 present the distributions of DIM at first and second insemination for 4 herds. The figures represent examples of how distributions of days to insemination are influenced by the management program used to control reproduction in herds. Figure 1 presents the distribution of days to first insemination (Figure 1a) and days to second insemination (Figure 1b) for a herd clearly using TAI for first insemination for almost all cows and using TAI to inseminate a significant proportion of second inseminations (herd 9 in Tables 4, 5, 6, and 7). Apparent in Figure 1a is a cluster of first inseminations occurring on d 70 to 76 postcalving. A cluster in a 7-d period such as this indicates a herd using a TAI program administered weekly. Forty-one percent of second inseminations were clustered in a3648 (Table 5) after first insemination or 111 to $117 \mathrm{~d}$ postcalving (Figure 1b). Additionally, $28.3 \%$ of second inseminations were classified in a1824 after first insemination (Table 5) and clustered at 88 to 100 DIM (Figure 1b). First insemination occurred only following a TAI program in this herd, and second insemination occurred following estrus detection (inseminations $<36 \mathrm{~d}$ from prior insemination) and TAI (inseminations a3648).

In contrast, Figure 2 presents insemination distributions for first (Figure 2a) and second (Figure 2b) insemination by DIM for a herd that reported using only heat detection for insemination (herd 16, Tables 4, 5, 6, and 7). Seventy-three percent of first inseminations occurred between 52 and $72 \mathrm{~d}$ postcalving with a uniform pattern across days, which decreases after $72 \mathrm{~d}$, as fewer cows are available to first inseminate. This corresponded to a first insemination rate of $78.8 \%$, calculated as the proportion of cows inseminated of those available to inseminate in 21-d periods from the oVWP. After the initial 21-d period, fewer animals are first inseminated, as fewer animals are available to inseminate for the first time. However, insemination rates remain high: $68.4 \%$ of available animals from 73 to $93 \mathrm{~d}$ and $63.5 \%$ of available animals from 94 to $114 \mathrm{~d}$ are inseminated (Figure 2a). Distribution of days to second insemination show a similar declining pattern with increasing DIM (Figure $2 \mathrm{~b}$ ). Between 18 and $24 \mathrm{~d}$ following first insemination, $55.2 \%$ of second inseminations occurred, with $12.3 \%$ of repeat inseminations as a3648 and only $10.7 \%$ classified as a49 after first insemination (Table 5).

In contrast, Figures 3 and 4 present insemination distributions for herds that inseminated cows seen in estrus following either PGF or GnRH injection before the PGF-GnRH-TAI Ovsynch protocol (Pursley et al., 1997). In Figure 3a and 3b (herd 1 in Tables 4, 5, 6, and 7), animals from 56 to 67 DIM were inseminated on observed estrus following either a $\mathrm{GnRH}$ injection given on d 57 to 63 postcalving or following a PGF injection given on d 64 to 70 postcalving. Cows not inseminated were then given a $\mathrm{GnRH}$ injection 66 to 72 DIM followed by TAI at 67 to 73 DIM (Figure 3a). This can be seen as the cluster of inseminations from 67 to 73 DIM in Figure 3a. Following this period, a low frequency of first inseminations continued from 75 to 115 DIM (Figure 3a). Distribution of DIM at second insemination is presented in Figure 3b. Cows were observed for estrus using tail chalk as an aid. Reproductive examinations were performed weekly at 37 to $43 \mathrm{~d}$ postinsemination using rectal palpation. All cows were given GnRH 1 wk before the reproductive examination (30-36 d postinsemination). Open cows were given PGF based on palpation findings; GnRH was injected $2 \mathrm{~d}$ following PGF and TAI followed on d 40 to 45 postinsemination at $16 \mathrm{~h}$ post-GnRH injection (herd 1 , Table 7 ). The postinsemination TAI program is apparent as the cluster of inseminations in Figure 3b between 111 and 117 DIM. Prior to the GnRH injection, cows were observed for estrus (apparent as inseminations occurring before 111 DIM; Figure 3b).

Figure 4 presents the distribution of first (Figure 4a) and second (Figure 4b) inseminations for herd 3 in Tables 4, 5, 6, and 7. All cows received PGF injections at 45 to 51 DIM and 59 to 65 DIM. Cows observed in estrus following the second PGF injection were inseminated using tail chalk as an estrus detection aid. Cows not inseminated following this injection received GnRH at 72 to 78 DIM, PGF at 79 to 85 DIM, GnRH at 81 to 87 DIM, and TAI at 82 to 88 DIM (Figure 4a). Distribution of first insemination follows a bimodal pattern with clusters at 63 to 68 DIM and at 82 to 88 DIM (Figure 4a). The early cluster of first inseminations occurred based on observed estrus following PGF injection; the second cluster of first inseminations followed the TAI program (Figure 4a). Second inseminations followed a trimodal pattern with clusters at 85 to 94 DIM, 103 to 114 DIM, and 124 to 130 DIM (Figure 4b). The first cluster of re-insemination represents cows inseminated on observed estrus between 84 to 92 DIM following the cluster of first inseminations between 63 and 68 DIM (Figures 4a and 4b). This is followed by a cluster of second inseminations between 103 and 114 DIM, corresponding to approximately $21 \mathrm{~d}$ following 
a)

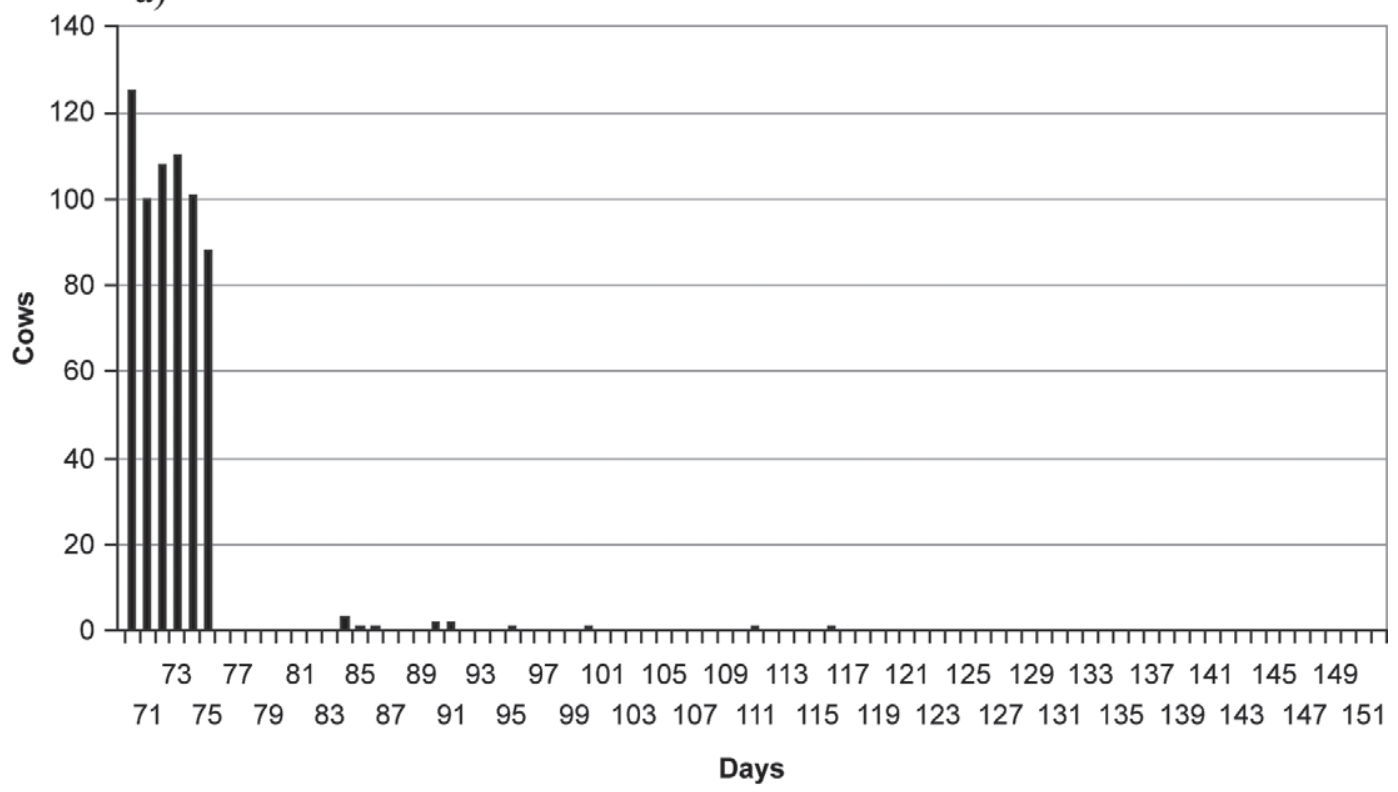

b)

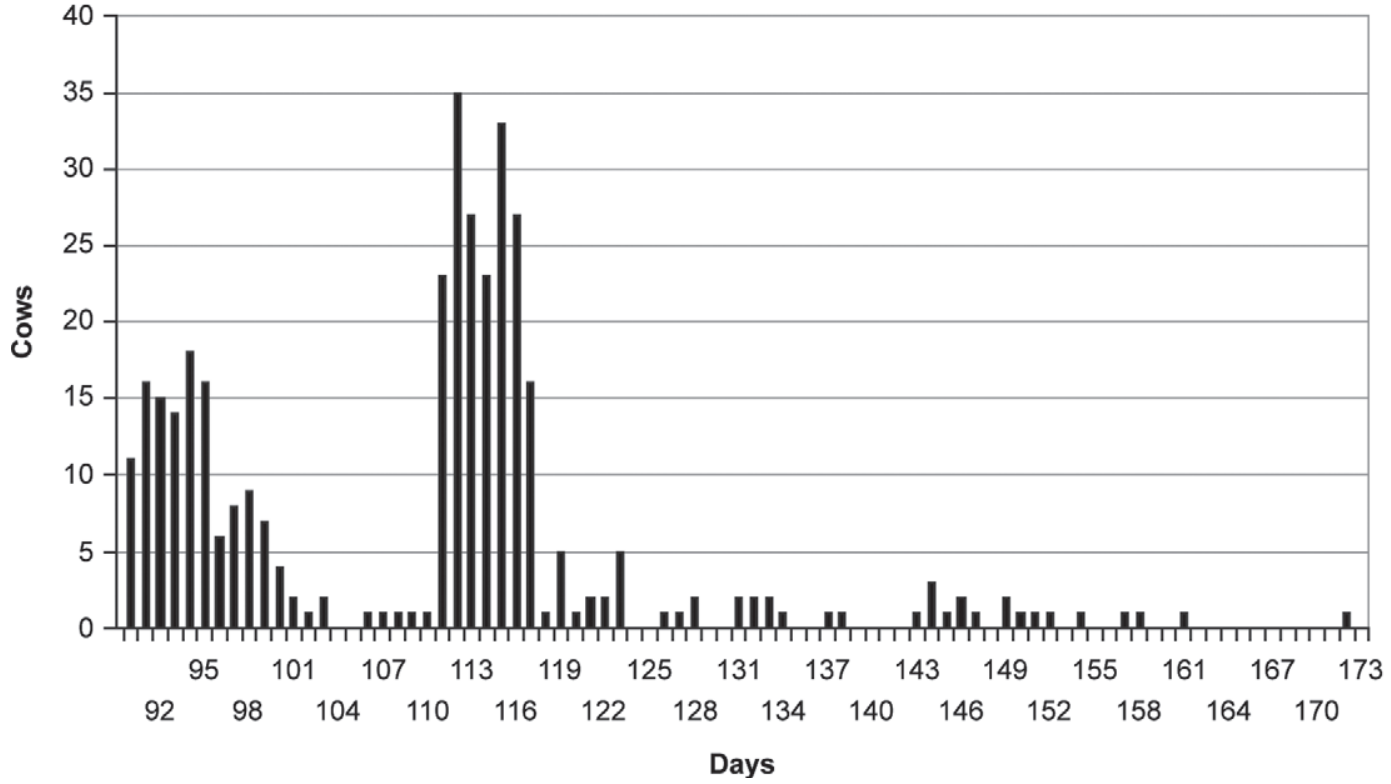

Figure 1. Distribution of DIM to (a) first insemination and (b) second insemination in herd 9 (Tables 3 and 4). First insemination (a): PreSynch-OvSynch program as follows: prostaglandin (PGF) 31-37 DIM; PGF 45-51 DIM; GnRH 59-65 DIM; PGF 66-72 DIM; GnRH/timed AI 69-75 DIM. Second insemination (b): tail chalk used as estrus detection aid; weekly pregnancy exam at 27 to $33 \mathrm{~d}$ postinsemination using ultrasound; open cows injected with GnRH, PGF 7 d later, and GnRH/timed AI 3 d after PGF.

the TAI cluster of first inseminations at 82 to 88 DIM (Figures $4 \mathrm{~b}$ and $4 \mathrm{a}$ ). Cows not seen in estrus by 30 to $36 \mathrm{~d}$ postinsemination were injected with GnRH. Reproductive examination occurred weekly at 37 to 43 $\mathrm{d}$ post insemination using ultrasound. Open cows were given PGF followed by GnRH at 39 to $45 \mathrm{~d}$ postinsemination and TAI at 40 to $46 \mathrm{~d}$ postinsemination, resulting in the cluster of second inseminations at 103 to 109 DIM and 124 to 130 DIM depending on days to first insemination (Figure 4b). Thus, TAI overlaps with heat detection in the second inseminations clustered at 103 to 114 DIM.

Analysis of a select set of herd reproductive data for herds classified by oVWP (50-59 d, 60-69 d, or $>70 \mathrm{~d})$ is presented in Table 8. Eight herds had an oVWP between 50 and 59d (VWP50), 4 herds between 60 and 69 
a)

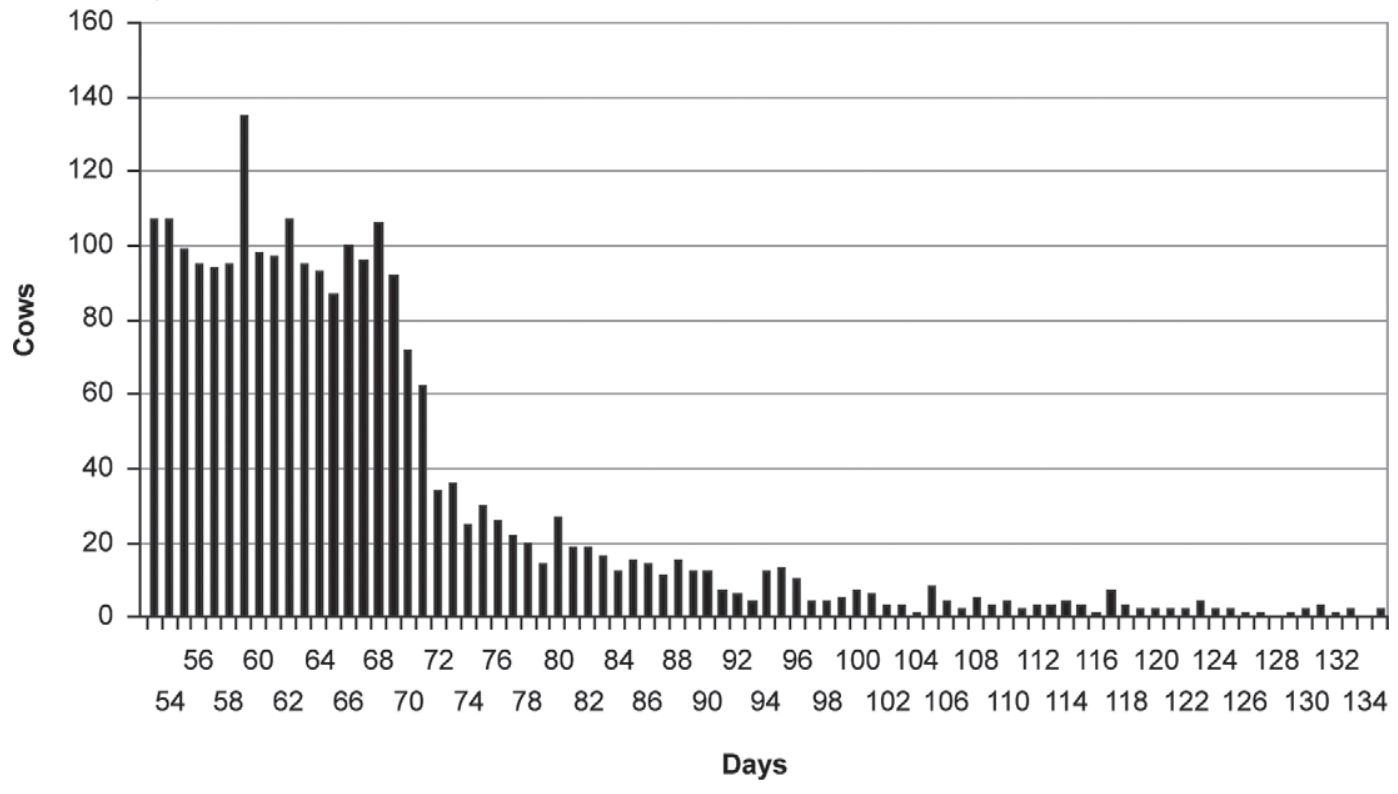

b)

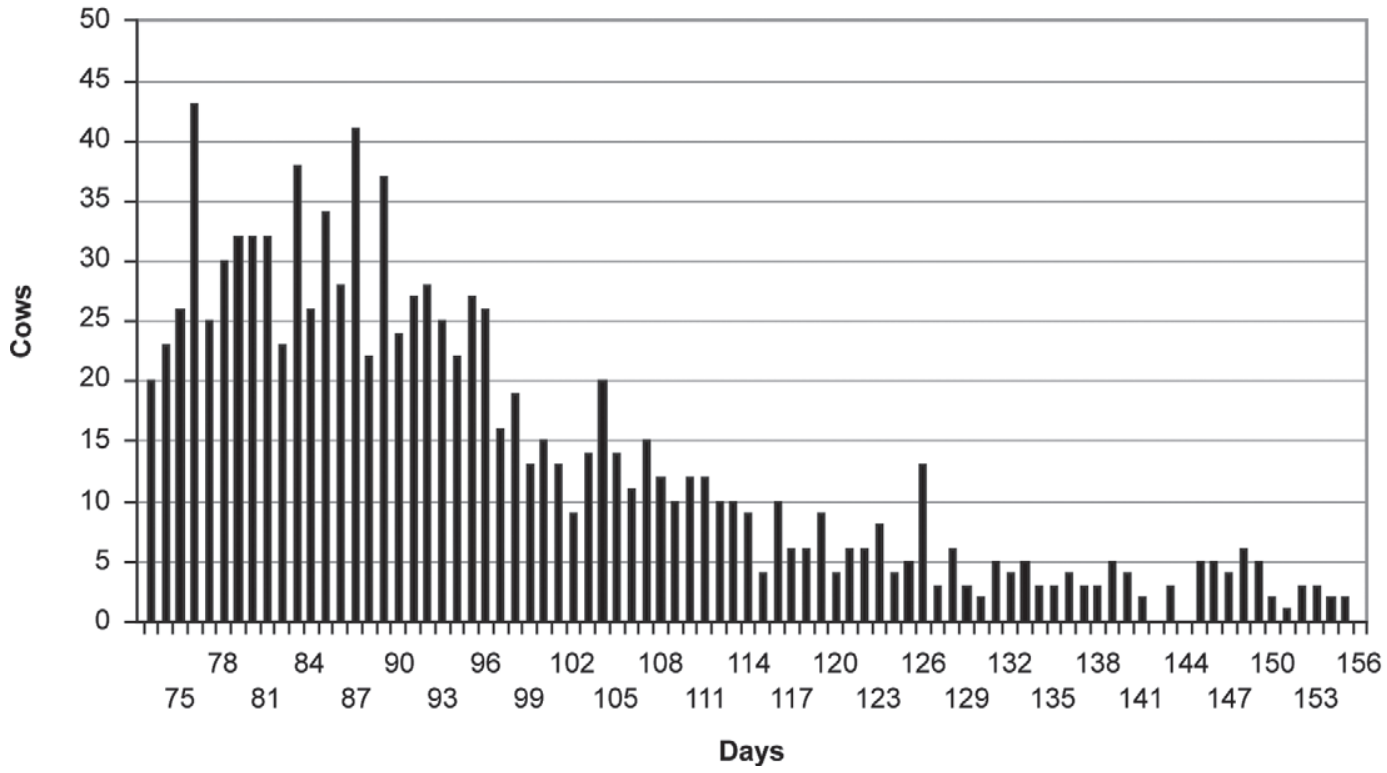

Figure 2. Distribution of DIM to (a) first insemination and (b) second insemination in herd 16 (Tables 3 and 4). First insemination (a): visual estrus detection aided by tail chalk was the primary method. Prostaglandin injected based on palpation findings in cows not seen in estrus to be observed using tail chalk. Second insemination (b): twice a month reproductive examinations for pregnancy at $\geq 35 \mathrm{~d}$ postinsemination using rectal palpation.

d (VWP60), and 4 herds between 70 and 79 d (VWP70; Table 8). One herd reported having an rVWP of $70 \mathrm{~d}$ for multiparous cows and $80 \mathrm{~d}$ for primiparous cows, but actual oVWP was between 70 and $79 \mathrm{~d}$ for both parity groups, so the herd was treated as having one oVWP. The mean oVWP was significantly different for the 3 VWP classes (VWP50, $52.7 \mathrm{~d}$; VWP60, 68.2 d, and
VWP70, 70.3 d, respectively, Table 8). The FSTIR was greater for VWP60 (FSTIR, 98.1) and VWP70 (97.2) compared with VWP50 (82.9, Table 8). More cows were first inseminated on a TAI protocol in herds with a longer VWP. Neither RPTIR nor FSTCR differed between herds (Table 8). Pregnancy rate was greater for VWP60 (34.8\%, SEM 1.8\%) and VWP70 (35.0\%, 
a)

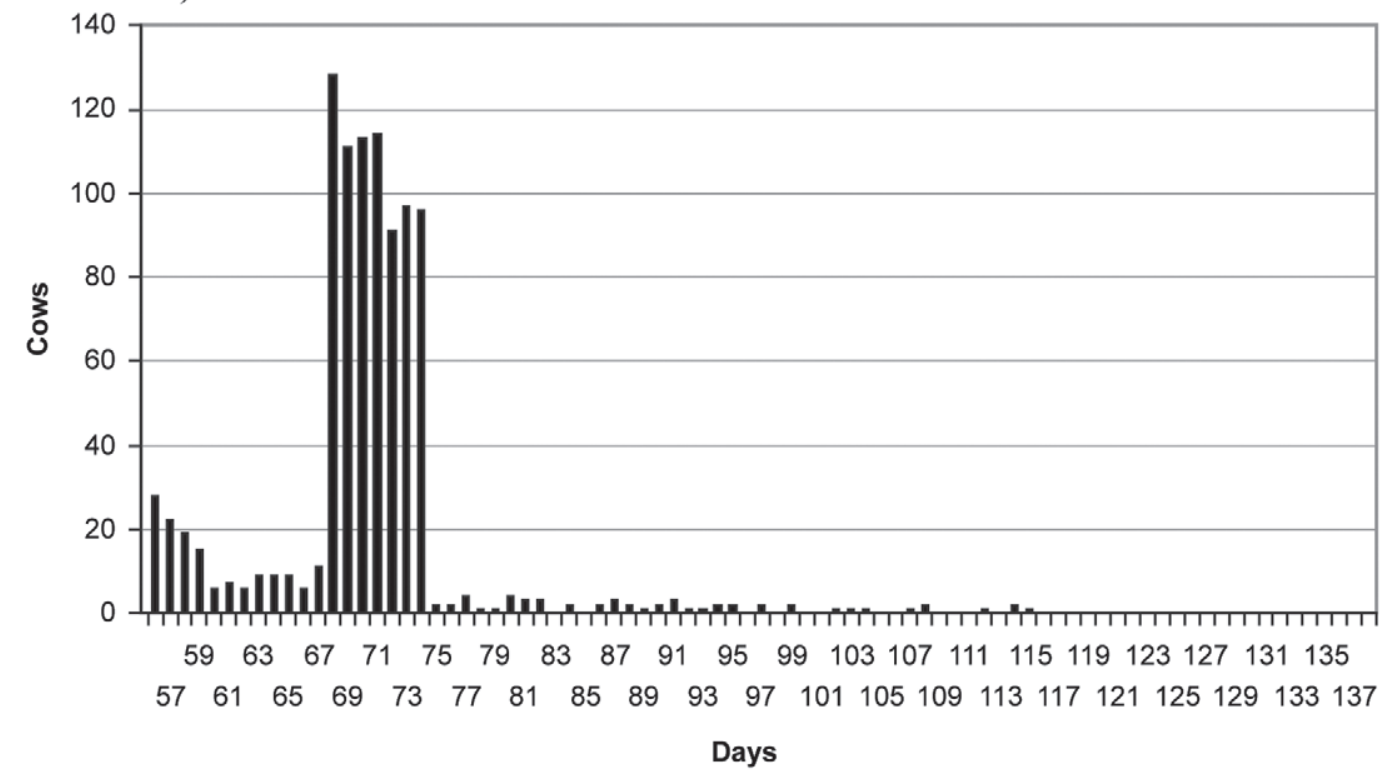

b)

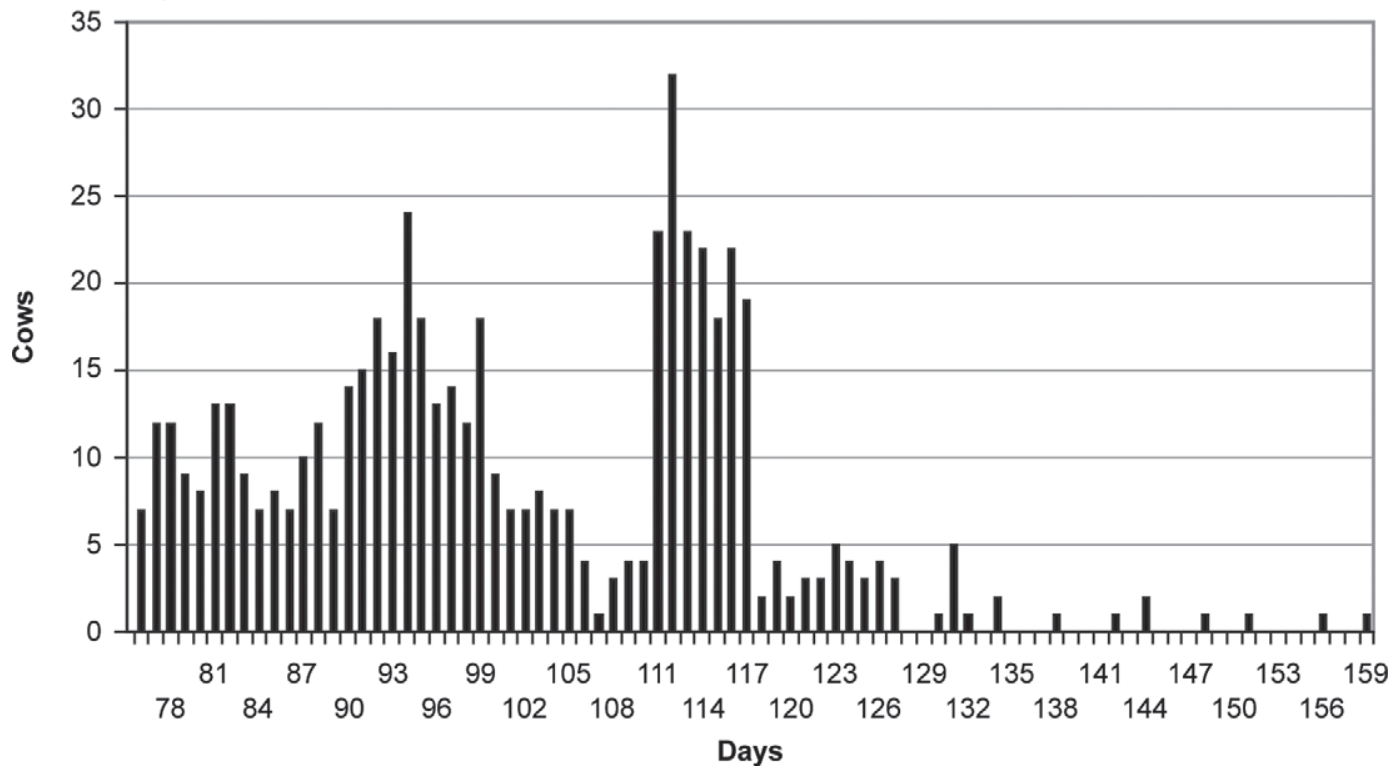

Figure 3. Distribution of DIM to (a) first insemination and (b) second insemination in herd 1 (Tables 3 and 4). First insemination (a): prostaglandin (PGF) 32-38 DIM; PGF 46-52 DIM; GnRH 57-63 DIM; PGF 64-70 DIM; GnRH 66-72 DIM; timed AI (TAI) 67-73 DIM; cows observed in estrus following GnRH 57-63 DIM and PGF 64-70 DIM are inseminated. Second insemination (b): cows observed for estrus using tail chalk as an aid; weekly reproductive examination at 37 to $43 \mathrm{~d}$ postinsemination using rectal palpation; cows given GnRH at 30 to $36 \mathrm{~d}$ postinsemination; open cows given PGF on d 37 to 43 postinsemination followed by GnRH on d 39 to 44 and TAI on d 40 to 45 postinsemination.

SEM 1.5\%) compared with VWP50 (28.6\%, SEM 1.0; Table 8). However, the value associated with reproduction was greater for VWP50 (\$463, SEM \$5) compared with VWP70 (\$432, SEM \$8), and it was intermediate for VWP60 (\$452, SEM \$8; Table 8). Although PR was greater in VWP70 and VWP60, the longer VWP delayed insemination and decreased economic value.
Figure 5 presents failure time curves for pregnancy for the herds classed by oVWP $(50,60$, and $70 \mathrm{~d}$, respectively): Figure 5 a presents the 8 herds with oVWP from 50 to 59 d; Figure 5b presents the 4 herds with oVWP of 61 to $69 \mathrm{~d}$; Figure $5 \mathrm{c}$ presents the 4 herds with oVWP of 70 to $79 \mathrm{~d}$. On each figure, reference curves for PR of 20, 30, and $40 \%$ are presented as dashed 
a)

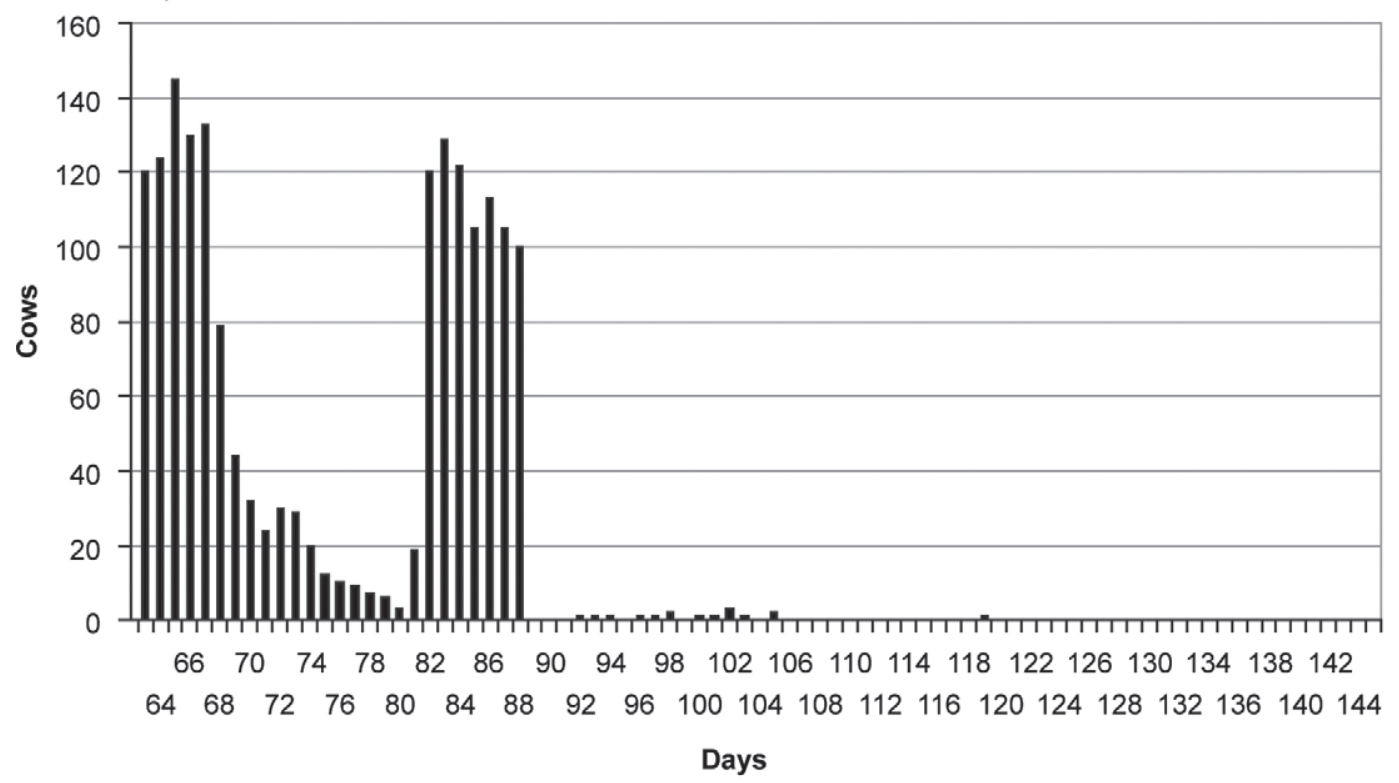

b)

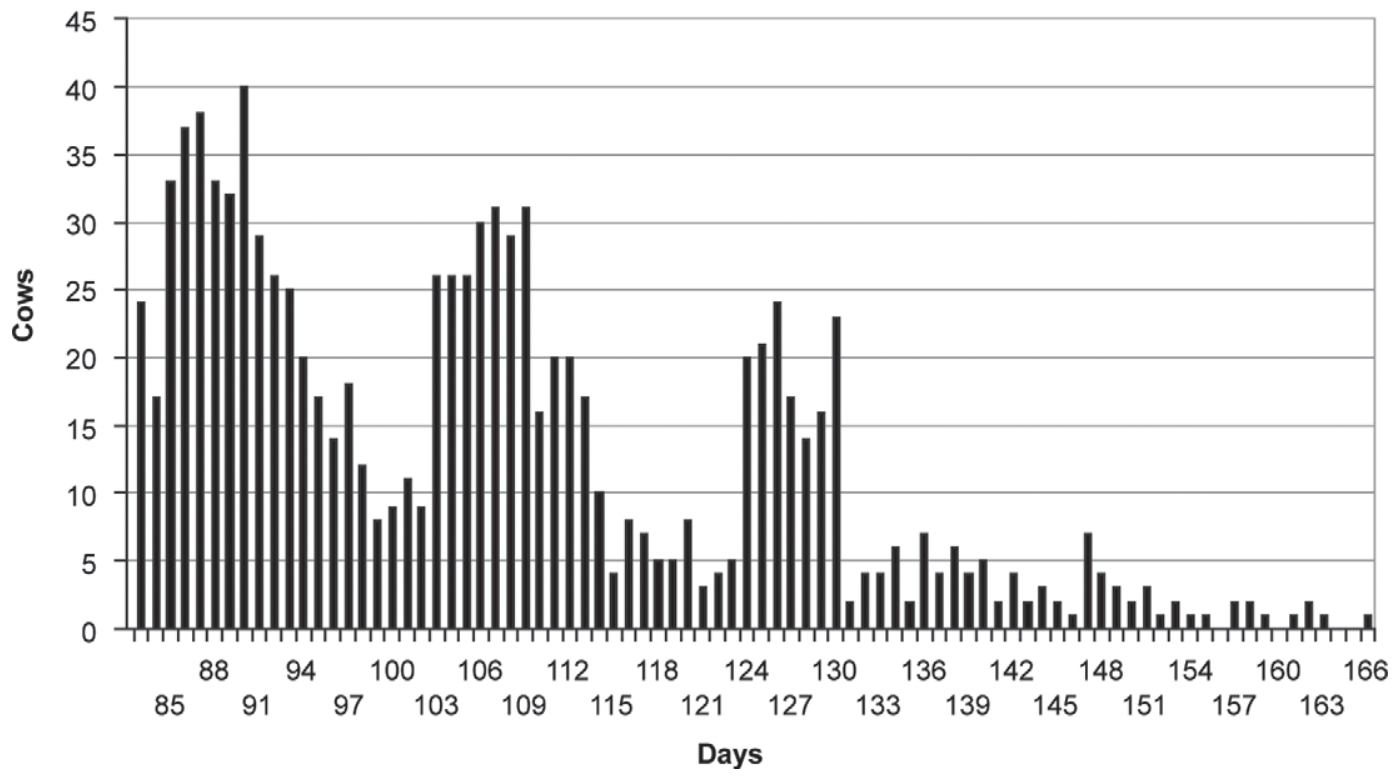

Figure 4. Distribution of DIM to (a) first insemination and (b) second insemination in herd 15 (Tables 3 and 4). First insemination (a): prostaglandin (PGF) 44-50 DIM; PGF 58-64 DIM, cows inseminated if estrus is observed using tail chalk as an aid; GnRH 72-78 DIM; PGF 79-85 DIM; GnRH 81-87 DIM; timed AI (TAI) 82-88 DIM. Second insemination (b): observed for estrus using tail chalk as an aid; cows not seen in estrus by 30 to $36 \mathrm{~d}$ postinsemination injected with $\mathrm{GnRH}$; pregnancy exam at 37 to 43 d postinsemination on weekly schedule using ultrasound; open cows receive PGF; GnRH injected at 39 to 45 d postinsemination; TAI at 40 to 46 d postinsemination.

curves. The majority of herds fell close to the $30 \% \mathrm{PR}$ curve, often obscuring the curve. As seen in Figure 5a and 5b, one herd in each group followed the $40 \% \mathrm{PR}$ curve until 92 to 103 DIM. As seen in Figure 5c, all herds were below the $30 \%$ PR curve before 114 DIM, approximate the $40 \%$ PR curve, and then follow the $30 \%$ PR curve. All but one of the herds deviated well below a 20\% PR except for 1 herd in Figure 5b, which approached and merged with the $20 \%$ PR curve after first service. Apparent are the high PR in these herds across all days postcalving for all 3 of the VWP classes.

Figure 6 presents mean failure time curves for the herds grouped by oVWP, VWP50, VWP60, and VWP70. Although the mean PR was greater for 
Table 8. Mean values for herds grouped by voluntary waiting period (VWP) of 50 (50 to $60 \mathrm{~d}$ ), 60 (60 to $70 \mathrm{~d}$ ), and 70 (70 to $80 \mathrm{~d})$

\begin{tabular}{|c|c|c|c|c|c|c|c|c|c|c|c|c|c|}
\hline VWP & $\begin{array}{c}\text { Herds, } \\
\text { No. }\end{array}$ & \multicolumn{2}{|c|}{$\mathrm{oVWP},{ }^{1} \mathrm{~d}$} & \multicolumn{2}{|c|}{ IRFST, $^{2} \%$} & \multicolumn{2}{|c|}{$\mathrm{IRRPT}^{3} \%$} & \multicolumn{2}{|c|}{ FSTCR, ${ }^{4} \%$} & \multicolumn{2}{|c|}{$\mathrm{PR},{ }^{5} \%$} & \multicolumn{2}{|c|}{$\mathrm{Val}^{6}{ }^{6} \$$} \\
\hline $50 \mathrm{~d}$ & 8 & $52.7^{\mathrm{a}}$ & 1.4 & $82.9^{\mathrm{a}}$ & 4.1 & 62.7 & 3.9 & 42.1 & 1.5 & $28.6^{\mathrm{a}}$ & 1.0 & $463^{\mathrm{a}}$ & 5 \\
\hline $70 \mathrm{~d}$ & 4 & $70.3^{\mathrm{c}}$ & 0.8 & $97.2^{\mathrm{b}}$ & 2.2 & 61.2 & 5.5 & 46.3 & 2.2 & $35.0^{\mathrm{b}}$ & 1.5 & $432^{\mathrm{b}}$ & 8 \\
\hline
\end{tabular}

${ }^{\mathrm{a}-\mathrm{C}}$ Values within a column with different superscripts differ by $P<0.05$.

${ }^{1} \mathrm{OVWP}=$ observed VWP based on distribution of days to first inseminations when either $5 \%$ of cows are first inseminated or the lowest day of first insemination if tightly clustered.

${ }^{2}$ IRFST $=$ insemination rate for first insemination based on distribution of days to first insemination in 21-d periods from the oVWP.

${ }^{3} \mathrm{IRRPT}=$ insemination rate for repeat inseminations based on the proportion of repeat inseminations $>49 \mathrm{~d}$ between inseminations; IRRPT $=(1-\text { proportion }>49 \mathrm{~d})^{.5}$.

${ }^{4} \mathrm{FSTCR}=$ conception rate for first insemination.

${ }^{5} \mathrm{PR}=$ pregnancy rate; the proportion of open cows that become pregnant every $21 \mathrm{~d}$ from the oVWP.

${ }^{6} \mathrm{Val}=$ mean annual value $(\$)$ for a pregnant cow based a milk price of $\$ 0.22 / \mathrm{kg}(\$ 0.10 / \mathrm{lb}), \$ 100 /$ male calf, $\$ 500 /$ cull cow, $\$ 1,200 /$ replacement heifer.

VWP60 and VWP70 compared with VWP50, the PR curve declined sooner for the VWP50 herds and remains below the PR curves for the other 2 VWP classes. The herds with later VWP, although declining faster, did so at later DIM. The area of difference represents the different economic value for the 3 VWP groupings. The earlier decline in the VWP50 herds is associated with a greater economic value compared with the VWP60 and VWP70 herds. Although PR is lower, the earlier decline provides the VWP50 herds a slight economic advantage compared with the VWP60 and VWP70 herds.

\section{DISCUSSION}

These 16 herds demonstrated excellent reproductive performance, as indicated by several parameters, including average DFS $<80 \mathrm{~d}$ in all herds, average BI $<40 \mathrm{~d}$ for all herds, and average PR $>25 \%$ for all herds. These compare with mean DFS values of $91.7 \mathrm{~d}$ (SD 23.5) and PR of 15.8\% (SD 5.7) for herds in the Raleigh DRMS system. These indices would rank these herds in the 99th percentile for PR in the Raleigh DRMS data and the bottom 18th percentile for DFS. However, the mean FSTCR of $44 \%$ and CRall of $39.1 \%$ (SD 3.5\%) across all herds compared with FSTCR for the Raleigh DRMS herds of $43.1 \%$ (SD 17.6), which would place them in the 50th percentile. Therefore, the excellent performance is associated with the superior insemination rates in these herds.

The excellent PR observed in these herds was due to average CRall combined with excellent insemination management. Historically, estrus detection determined insemination intensity and HDR could be considered synonymous with insemination rate. With the advent of TAI programs, insemination may occur independently of estrus detection. However, this paper continues to use insemination as a proxy for estrus detection, because only approximately $20 \%$ of herds use synchronization programs (Norman et al., 2009), and even in herds using synchronization programs, a significant proportion of inseminations occur following estrus detection, such was the case in these herds. Managers estimated that 21 to $94 \%$ of inseminations occurred following estrus detection in herds using TAI (Table 4).

First insemination is an extremely important control point in reproductive management. Morton (2010) observed that PR in the first 21 or $42 \mathrm{~d}$ following initiation of insemination was strongly influenced by intensity of insemination within this period. First insemination rates assess this intensity and ranged from 74.5 to $99.8 \%$ in these herds (Table 5). These high rates were associated with a mix of TAI and estrus detection in many of these herds. Insemination rates in DHIA data are assessed as heats observed or as average service rates (Table 1) and include repeat inseminations and first inseminations in one variable. First-service insemination rates for these herds would rank them in the 97th to 99th percentiles for insemination rates for first service compared with the mean heat observation rate in Table 1.

Morton (2010) observed that CR for inseminations within the 21- and 42-d periods following the VWP were as important in determining PR. First-service CR in these herds placed them in the 50th percentile of herds in the Raleigh DHIA summary statistics (Table $1)$. These herds had average CR. However, CR is dependent on insemination; therefore, a first priority in managing reproductive efficiency is control of FSTIR. Although FSTCR was more highly correlated with PR in this data than FSTIR, FSTIR was better than observed on most farms. This likely dampened the importance of FSTIR relative to FSTCR on PR in this data. First-service CR is dependent on FSTIR, and farms 
a)

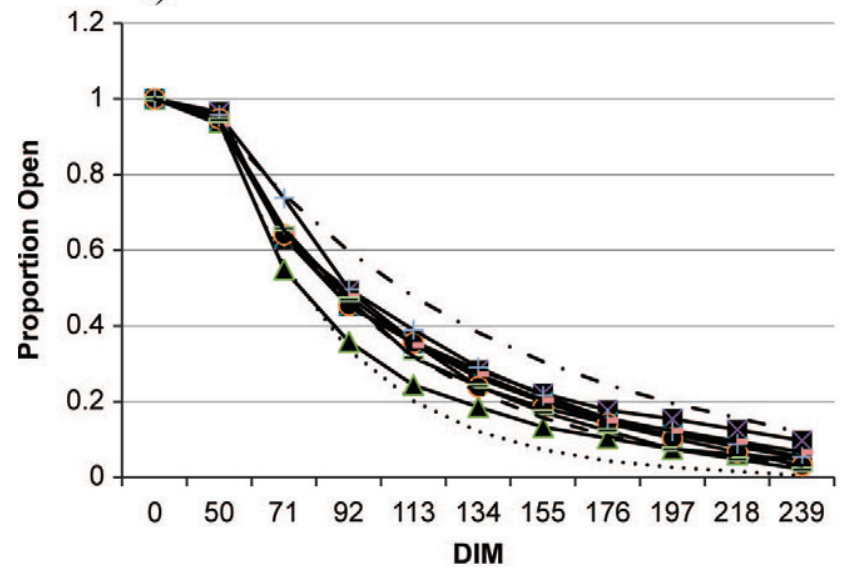

b)

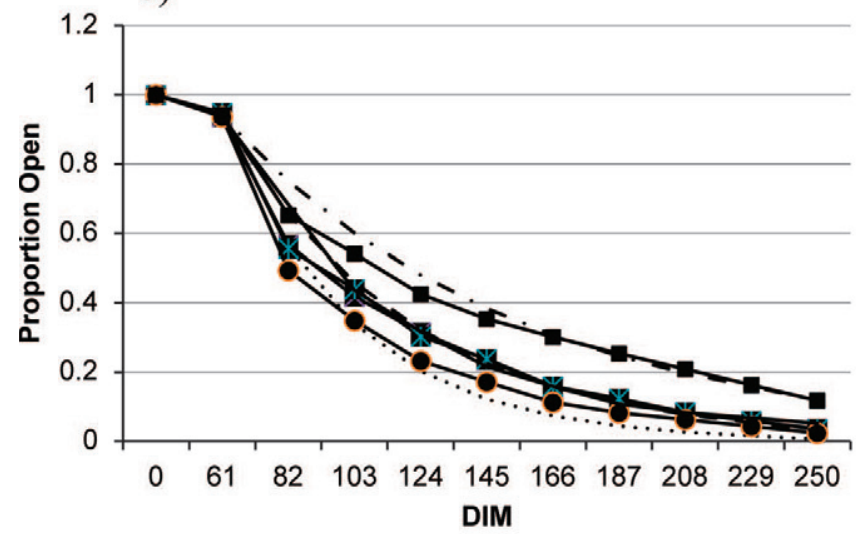

c)

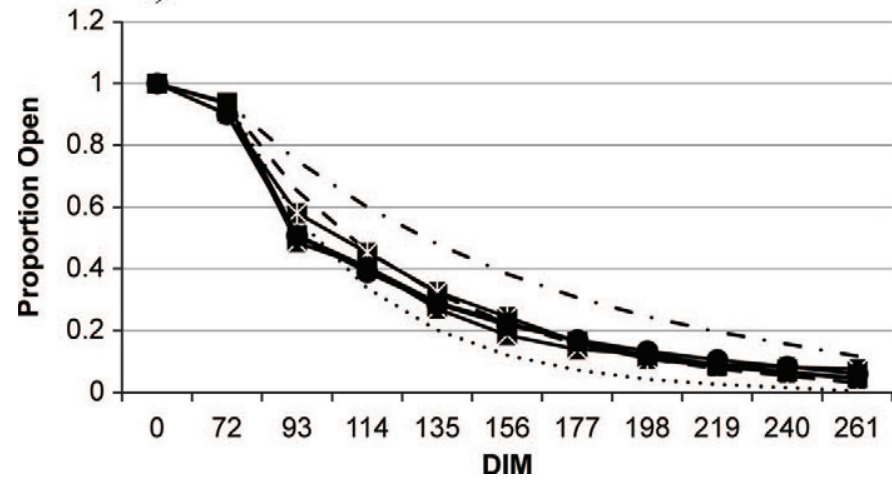

Figure 5. Failure time curves for pregnancy by days postcalving for herds (represented by symbols) with (a) 50 to $59 \mathrm{~d}$ observed VWP (7 herds); (b) 61 to $69 \mathrm{~d}$ VWP (5 herds); and (c) 70 to $73 \mathrm{~d}$ VWP (4 herds). Curves represent the proportion of cows open (y-axis) by time postcalving (x-axis). Dashed lines represent pregnancy rate curves for $0.20(-.-), 0.30(---)$, and $0.40(\cdots)$ on each figure. Observed VWP was estimated from DIM by which $5 \%$ of first inseminations had occurred. VWP = volunteer waiting period. Color version available in the online PDF. should first focus on managing FSTIR to increase reproductive efficiency.

Repeat insemination rates, estimated as 21 divided by the mean BI for each herd or, as in this paper, as $1-\mathrm{a} 49^{0.5}$, ranked these herds in the top 65 th to 99th percentiles using heats observed and SD from DHIA data in Table 1. Combined, FSTIR and RPTIR estimated from the insemination distributions in these herds ranked them in the top 1 to $2 \%$ of herds for insemination compared with heats observed, as assessed from data in Table 1. The high insemination rates were due to controlled first insemination programs and consistent repeat insemination programs.

Schefers et al. (2010) observed that use of a resynchronization protocol was an important factor in increasing service rates on dairy farms. Resynchronization protocols may only increase service rates for second and higher services. Morton (2010) found that service rate for first insemination and conception rate at first service were equally important to increasing PR in the first 21 and $42 \mathrm{~d}$ following the VWP in seasonal and year-round breeding herds. The high reproductive efficiency in these herds highlights the importance of managing both first and repeat insemination through the herd reproductive program.

First insemination heavily influences PR because all cows are exposed to first insemination and it influences the early part of the survival function from the VWP. As seen in Figure 5, managing first insemination rapidly declines failure time curves following the oVWP. Giordano et al. (2011) observed that TAI programs were economically superior to programs dependent on estrus detection when HDR rates were $50 \%$. Giordano et al. (2011) further observed that resynchronization programs that were associated with an increase in CR were economically superior to those implemented sooner postinsemination but had lower CR. Therefore, a tradeoff with time exists, whether associated with VWP for first insemination or BI associated with reinsemination, $\mathrm{CR}$, and insemination intensity as to the most economic program for use in a herd. Earlier insemination with lower CR may extend time to pregnancy by causing a delay in DIM to a fertile insemination (Giordano et al., 2011).

Pregnancy rate was greater for herds with later VWP (Table 8). Schefers et al. (2010) and other authors (Pursley et al., 1997; Tenhagen et al., 2004; Caraviello et al., 2006) have observed greater CR with later VWP. However, in these herds, FSTCR and CRall did not differ with VWP class, but PR was greater due to greater FSTIR in herds with later VWP. Herds with later VWP inseminated a higher proportion of cows using TAI for first insemination as estimated from distributions of first inseminations. Days to first insemina- 


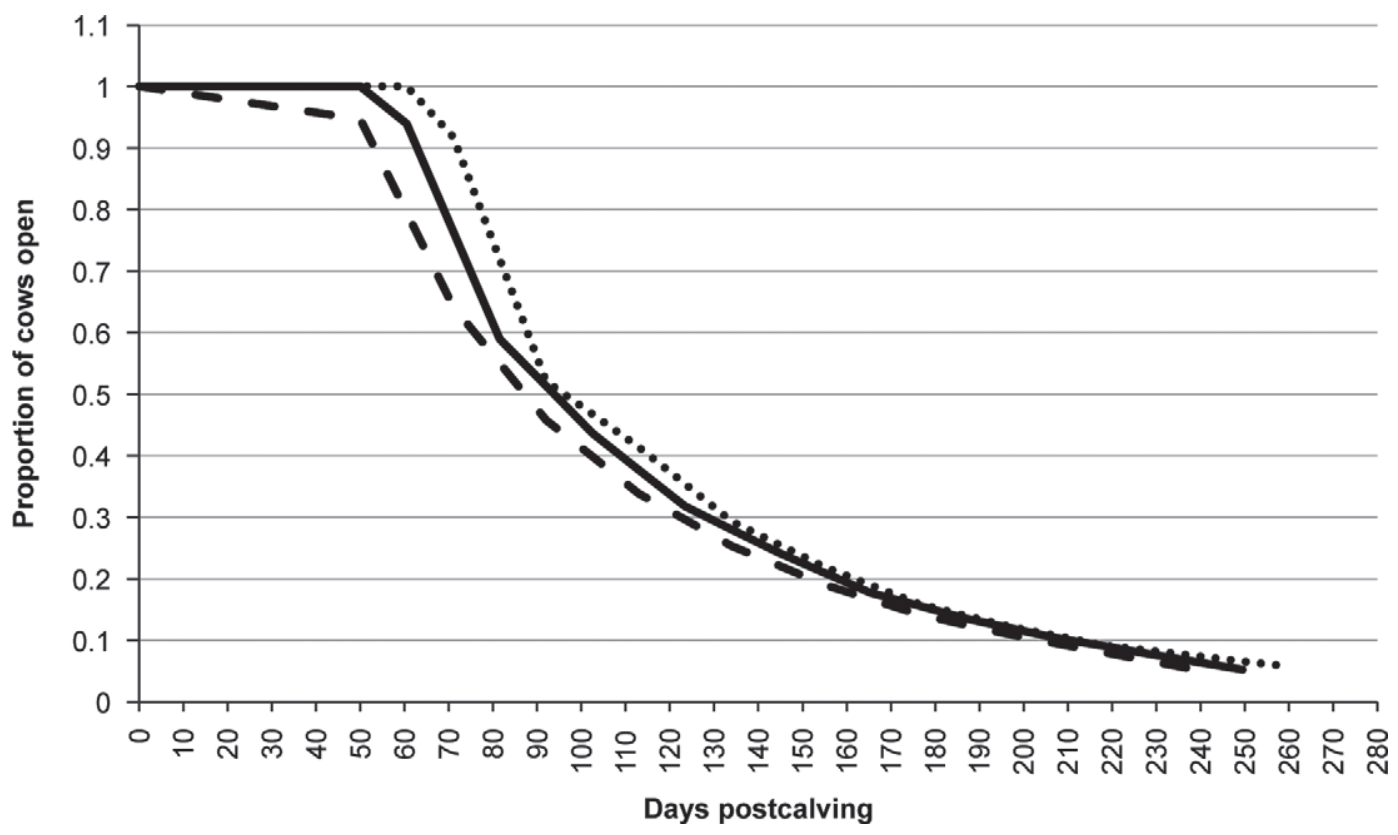

Figure 6. Mean failure time curves for herds classed by observed VWP (oVWP) of 50 to $59 \mathrm{~d}$ (dashed line), 60 to $69 \mathrm{~d}$ oVWP (solid line), and $>70 \mathrm{~d}$ oVWP (dotted line). Observed VWP was estimated from DIM by which $5 \%$ of first inseminations had occurred. VWP $=$ volunteer waiting period.

tion was greater with extended VWP in these herds. However, CR was sufficient in the VWP50 herds that the proportion of cows pregnant at earlier DIM was greater than for the VWP60 and VWP70 herds, giving the VWP50 herds an economic advantage.

Sørensen and Østergaard (2003) observed that delaying first insemination reduced herd profit unless offset with reduced labor costs. Although herds with later VWP had higher PR, economic value was slightly reduced due to the delay in first insemination (Table 8). Pregnancy rate was sufficient to maintain the advantage in pregnancy decline, as seen in Figure 6, for the herds with earlier VWP. Conception rate did not differ across VWP; therefore, a sufficient proportion of cows became pregnant sooner with earlier VWP to have greater economic value ( $\$ 31$ higher value for herds with oVWP of 50 to $59 \mathrm{~d}$ versus herds with a oVWP $>70 \mathrm{~d}$ ). The CR would have to have been significantly greater in VWP60 and further increased in VWP70 herds to have matched the economic value of VWP50 herds. Herd managers should carefully evaluate the optimal VWP within their herds and occasionally test whether earlier or later inseminations would be advantageous.

These herds were located in the eastern US (5 in NY), the Midwest ( 5 in WI, 1 in IA, 1 in SD), and the western US ( 2 in CA, 1 in OR, 1 in WA). Reproductive data vary by region (Table 1) with lower efficiency in the south, evidenced by longer DFS and days open, and lower $\mathrm{CR}$ in the west. No herds were from the south or southwest, regions in which heat stress may limit achieving the reproductive performance observed in these herds. In Table 1, it can be seen that CR was similar for the south compared with the east and Midwest in DHIA summary data, but DFS and days open were significantly greater and heats observed were lower than for the east, Midwest, and west. Seasonal effects that delay ovulation postcalving, reduce CR, and increase ED would all function to reduce reproductive performance. However, within a herd, improving insemination rates may improve reproductive performance if $\mathrm{CR}$ and ED remained at comparable rates as before the application of a managed breeding program.

Miller et al. (2007) observed that herds identified as having synchronized breeding programs had fewer DFS than herds with no evidence of synchronized inseminations. However, in that data, DFS was compared across herds from 33 million services, representing a sample of the US population of herds. Thus, herds estimated as using synchronized programs had fewer DFS than the population. In this data set, a select group of herds was being compared, so herds with a greater proportion of TAI for first insemination had longer DFS. However, across the entire group of herds in this study, all herds had lower DFS than the mean observed in Table 1, even for herds with a VWP $>70 \mathrm{~d}$.

Norman et al. (2009) observed that mean DFS in aggregated DHIA records decreased in Holstein cows from 1996 to 2007, from 92 to 85 d, which was still 
greater than observed in the herds of the current study. Days to first insemination were slightly lower in Jersey cattle, 83 d in 2007 (Norman et al., 2009), but still greater than observed in the current data. Mean FSTCR in 2007 in Norman et al. (2009) for Holstein and Jersey cattle were lower than in this study (32 and $39 \%$ for Holstein and Jersey, respectively). Mean BI was significantly greater in Norman et al. (2009) for Holstein (69 d in 2006) and Jersey (55 d in 2006) cows than observed for these herds in the current study. The lower values for DFS and BI reflect the high intensity of insemination in these herds, as seen in the FSTIR and RPTIR values. We observed a tendency for the mean values for CRall to be greater for the mixed breed and Jersey herds combined compared with the Holstein herds (CRall, 41.3 vs. $37.6 \%$, respectively; $P<0.07$ ) but not for FSTCR (46.9 vs. $43.7 \%$; $P<0.25$, respectively). The number of observations in this study was too few to detect breed differences.

It would be inappropriate to credit the high PR in these herds solely to good heat detection, as all but one herd reported using some TAI program for first and repeat inseminations. The 2 herds that did not complete the survey had evidence of TAI based on patterns for first insemination (data not shown). Herds using TAI typically show the first insemination distributions as seen in Figure 1a. All but one herd reported using TAI for first insemination, resulting in an FSTIR of $86.9 \%$ across all herds. The mean days between inseminations were $33.4 \mathrm{~d}$, suggesting a RPTIR between 60 and $70 \%$, which, according to Heersche and Nebel (1994), corresponds to mean days between inseminations of 30 and $35 \mathrm{~d}$. Synchronization of first insemination typically resulted in clustering of DIM at second insemination, which, combined with re-synchronization programs, increased estrus detection rates for re-insemination. The effect of TAI inflates estimates of heat detection as it enables insemination independently of actual observation of estrus. Most herds amplified TAI programs with heat detection aids, the most common method being chalk or crayon marks applied to the tail head region. Heat detection aids may increase cows inseminated due to secondary signs of estrus, but this often increases heat detection errors, suggested by the increase in abnormal insemination intervals (Heersche and Nebel, 1994). Schefers et al. (2010) observed that an increase in insemination intervals between 4 and $17 \mathrm{~d}$ resulted in a reduction in CR. In these herds, the a10, a1017, and a2535 intervals had no association with any estimate of CR or with any reported TAI program. Misallocation of cows to the TAI protocol, thus reducing synchronization of ovulation, may result in an increase in abnormal intervals to repeat insemination if the herd was also using estrus detection to control insemination. If injec- tion schedules were misapplied, it would be expected that FSTCR would be reduced compared with repeat service rates and this was not the case in any of the herds.

Herds with every-other-week pregnancy diagnosis programs had a greater proportion of a2535 intervals. Examination at 27 to $29 \mathrm{~d}$ postinsemination and injecting PGF if a corpus luteum was determined to be present on an ovary could result in insemination between 30 and $35 \mathrm{~d}$ postinsemination if cows were observed in estrus following injection. However, herds that reported using PGF in cows at pregnancy examination (herds $3,7,10$; Table 7) did not show a higher proportion of a2535 than other herds (Table 5). The proportion of abnormal intervals was not associated with any specific heat detection aid reportedly used in these herds. Herds using pedometers (2 herds) as heat detection aids did not show a higher proportion of irregular inseminations than other herds and no greater frequency of a1824 inseminations.

Utilization of routine pregnancy examination on a weekly or every 2 wk basis was used equally across farms. Theoretically, weekly herd visits should result in a lower proportion of cows with days between inseminations greater than $48 \mathrm{~d}$ at a given heat detection rate. However, herds with weekly herd visits had a mean proportion of a 49 inseminations of $13.1 \%$ (SD $=4.35 \%$ ), and herds with herd visits every other week had a mean proportion of a49 inseminations of $14.1 \%$ ( $\mathrm{SD}=4.89 \%)$, so no advantage to weekly herd visits was found in this data set based on this index. Management of re-insemination was high on all these herds, negating any benefit of more frequent reproductive examinations.

In these data, PR was greater when FSTIR $(\mathrm{r}=0.55$, $P<0.026)$, FSTCR $(\mathrm{r}=0.72, P<0.002)$, and CRall $(\mathrm{r}=0.65, P<0.007)$ were greater and was associated with a later oVWP. Many factors may influence CR in a dairy herd. Herds in this data set used estrus detection and TAI programs with various schedules for insemination relative to $\mathrm{GnRH}$ injection. We found no apparent benefit to any of the varying schedules used in this group of herds. The important component was consistently applying a program. Differences in factors across herds would obscure any benefits of one schedule compared with other schedules of insemination relative to GnRH injection.

\section{CONCLUSIONS}

This selective survey of reproductive performance demonstrated that management programs that control insemination result in high reproductive efficiency when $\mathrm{CR}$ is average. Insemination was controlled through 
a combination of TAI, insemination following estrus detection using visual observation and secondary aids, and weekly or every other week veterinary diagnosis of nonpregnancy status combined with a resynchronization program.

\section{ACKNOWLEDGMENTS}

We thank the producers and advisors who participated in the project for sharing their records and information on their reproductive management. In addition, we thank Merck (Whitehouse Station, NJ) for supporting this project.

\section{REFERENCES}

Britt, J. H., R. G. Scott, J. D. Armstrong, and M. D. Whitacre. 1986. Determinants of estrous behavior in lactating Holstein cows. J. Dairy Sci. 69:2195-2202.

Caraviello, D. Z., K. A. Weigel, P. M. Fricke, M. C. Wiltbank, M. J. Florent, N. B. Cook, K. V. Nordlund, N. R. Zwald, and C. L. Rawson. 2006. Survey of management practices on reproductive performance of dairy cattle on large US commercial farms. J. Dairy Sci. 89:4723-4735.

Coleman, D. A., W. V. Thayne, and R. A. Dailey. 1985. Factors affecting reproductive performance of dairy cows. J. Dairy Sci. 68:1793-1803.

Dewey, S. T., L. G. D. Mendonça, G. Lopes Jr., R. A. Rivera, F. Guagnini, R. C. Chebel, and T. R. Bilby. 2010. Resynchrionization strategies to improve fertility in lactating dairy cows utilizing a presynchronization injection of GnRH or supplemental progesterone: I. Pregnancy rates and ovarian responses. J. Dairy Sci. 93:4086-4095.

Dransfield, M. B. G., R. L. Nebel, R. E. Pearson, and L. D. Warnick. 1998. Timing of insemination for dairy cows identified in estrus by radiotelemetric estrus detection system. J. Dairy Sci. 81:1874-1882.

Ferguson, J. D., and D. T. Galligan. 1993a. Prostaglandin synchronization programs in dairy herds: Part 1. Compend. Cont. Educ. North Am. 15:646-654.

Ferguson, J. D., and D. T. Galligan. 1993b. Prostaglandin synchronization programs in dairy herds: Part 2. Compend. Cont. Educ. North Am. 15:1127-1130.

Fricke, P. M., D. Z. Caraviello, K. A. Weigel, and M. L. Welle. 2003. Fertility of dairy cows after resynchronization of ovulation at three intervals following first timed insemination. J. Dairy Sci. 86:3941-3950.

Garnsworthy, P. C., K. D. Sinclair, and R. Webb. 2008. Integration of physiological mechanisms that influence fertility in dairy cows. Animal 2:1144-1152.

Giordano, J. O., P. M. Fricke, M. C. Wiltbank, and V. E. Cabrera. 2011. An economic decision-making support system for selection of reproductive management programs on dairy farms. J. Dairy Sci. 94:6216-6232.

Grimard, B., S. Freret, A. Chevallier, A. Pinto, C. Ponsart, and P. Humblot. 2006. Genetic and environmental factors influencing first service conception rate and late embryonic/foetal mortality in low fertility dairy herds. Anim. Reprod. Sci. 91:31-44.

Heersche, G., and R. L. Nebel. 1994. Measuring efficiency and accuracy of detection of estrus. J. Dairy Sci. 77:2754-2761.

Inchaisri, C., R. Jorritsma, P. L. A. M. Vos, G. C. van der Weijden, and H. Hogeveen. 2011. Analysis of the economically optimal voluntary waiting period for first insemination. J. Dairy Sci. 94:3811-3823.
Lopez, H., L. D. Satter, and M. C. Wiltbank. 2004a. Relationship between level of milk production and estrous behavior of lactating dairy cows. Anim. Reprod. Sci. 81:209-223.

Lopez, H., Z. Wu, L. D. Satter, and M. C. Wiltbank. 2004b. Effect of dietary phosphorus on estrous behavior of lactating dairy cows. Theriogenology 61:437-445.

Lucy, M. C. 2001. Reproductive loss in high-producing dairy cattle: Where will it end? J. Dairy Sci. 84:1277-1293.

Meadows, C., P. J. Rajala-Schultz, and G. S. Frazer. 2005. A spreadsheet-based model demonstrating the nonuniform economic effects of varying reproductive performance in Ohio dairy herds. J. Dairy Sci. 88:1244-1254.

Miller, R. H., H. D. Norman, M. T. Kuhn, J. S. Clay, and J. L. Hutchison. 2007. Voluntary waiting period and adoption of synchronized breeding in dairy herd improvement herds. J. Dairy Sci. 90:1594-1606.

Morton, J. M. 2010. Interrelationships between herd-level reproductive performance measures based on intervals from initiation of the breeding program in year-round and seasonal calving dairy herds. J. Dairy Sci. 93:901-910.

Norman, H. D., J. R. Wright, S. M. Hubbard, R. H. Miller, and J. L. Hutchinson. 2009. Reproductive status of Holstein and Jersey cows in the United States. J. Dairy Sci. 92:3517-3528.

Oltenacu, P. A., T. R. Rounsaville, R. A. Milligan, and R. H. Foote. 1981. Systems analysis for designing reproductive programs to increase production and profit in dairy herds. J. Dairy Sci. 64:2096-2104.

Pennington, J. A., J. L. Albright, and C. J. Callahan. 1986. Relationships of sexual activities in estrous cows to different frequencies of observation and pedometer measurements. J. Dairy Sci. 69:2925-2934

Pursley, J. R., M. R. Kosorok, and M. C. Wiltbank. 1997. Reproductive management of lactating dairy cows using synchronization of ovulation. J. Dairy Sci. 80:301-306.

Raleigh DRMS. 2012. Dairy Metrics. Accessed June 2012. http:// www.drms.org/dairymetricsinfo.aspx?node_id=Dflt6. Raleigh DRMS, Raleigh, NC.

Rosner, B. 2006. Hypothesis testing: Person-time data. Pages 781-810 in Fundamentals of Biostatistics. 6th ed. Thomson Higher Education, Belmont, CA.

Santos, J. E. P., W. W. Thatcher, R. C. Chebel, R. L. A. Cerri, and K. N. Galvão. 2004. The effect of embryonic death rates in cattle on the efficacy of estrus synchronization programs. Anim. Reprod. Sci. 82-83:513-535.

Schefers, J. M., K. A. Weigel, C. L. Rawson, N. R. Zwald, and N. B. Cook. 2010. Management practices associated with conception rate and service rate of lactating Holstein cows in large, commercial dairy herds. J. Dairy Sci. 93:1459-1467.

Sheldon, I. M., G. S. Lewis, S. LeBlanc, and R. O. Gilbert. 2006 Defining postpartum uterine disease in cattle. Theriogenology 65:1516-1530.

Sørensen, J. T., and S. Østergaard. 2003. Economic consequences of postponed first insemination of cows in a dairy cattle herd. Livest. Prod. Sci. 79:145-153.

Sveberg, G., A. O. Refsdal, H. W. Erhard, E. Kommisrud, M. Aldrin, I. F. Tvete, F. Buckley, A. Waldmann, and E. Ropstad. 2011. Behavior of lactating Holstein-Friesian cows during spontaneous cycles of estrus. J. Dairy Sci. 94:1289-1301.

Tenhagen, B. A., M. Drillich, R. Surholt, and W. Heuwieser. 2004. Comparison of timed AI after resynchronized ovulation to AI at estrus: Reproductive and economic considerations. J. Dairy Sci. $87: 85-94$

Weigel, K. A. 2006. Prospects for improving reproductive performance through genetic selection. Anim. Reprod. Sci. 96:323-330.

Willard, S., S. Gandy, S. Bowers, K. Graves, A. Elias, and C. Whisant. 2003. The effects of GnRH administration postinsemination on serum concentrations of progesterone and pregnancy rates in dairy cattle exposed to mild summer heat stress. Theriogenology 59:1799-1810. 